\title{
An international review of laser Doppler vibrometry: making light work of vibration measurement
}

\author{
${ }^{1}$ Rothberg, S.J, ${ }^{2}$ Allen, M.S., ${ }^{3}$ Castellini P., ${ }^{4}$ Di Maio, D., ${ }^{5}$ Dirckx, J.J.J., ${ }^{6}$ Ewins, D.J., \\ ${ }^{1}$ Halkon, B.J., ${ }^{5}$ Muyshondt, P., ${ }^{3}$ Paone N., ${ }^{7}$ Ryan, T., ${ }^{8}$ Steger, H., ${ }^{3}$ Tomasini, E.P., \\ ${ }^{9}$ Vanlanduit, S., ${ }^{10}$ Vignola, J.F.
}

1. School of Mechanical, Electrical and Manufacturing Engineering, Loughborough University, UK.

2. Department of Engineering Physics, University of Wisconsin - Madison, US

3. Department of Industrial Engineering and Mathematical Sciences, Polytechnic University of Marche, Italy

4. Department of Mechanical Engineering, University of Bristol, UK

5. Department of Physics, University of Antwerp, Belgium

6. Department of Mechanical Engineering, Imperial College London, UK

7. Department of Engineering, East Carolina University, Greenville, US

8. Polytec GmbH, Waldbronn, Germany

9. Department of Electromechanics, University of Antwerp, Belgium

10. Department of Mechanical Engineering, Catholic University of America, Washington, DC, US

Corresponding author: Steve Rothberg

e-mail: s.j.rothberg@lboro.ac.uk

tel: +44 (0) 1509223440

DOI: 10.1016/j.optlaseng.2016.10.023

(C) 2016. This manuscript version is made available under the CC-BY-NC-ND 4.0 license http://creativecommons.org/licenses/by-nc-nd/4.0/ 


\title{
An international review of laser Doppler vibrometry: making light work of vibration measurement
}

\author{
${ }^{1}$ Rothberg, S.J, ${ }^{2}$ Allen, M.S., ${ }^{3}$ Castellini P., ${ }^{4}$ Di Maio, D., ${ }^{5}$ Dirckx, J.J.J., ${ }^{6}$ Ewins, D.J., \\ ${ }^{1}$ Halkon, B.J., ${ }^{5}$ Muyshondt, P., ${ }^{3}$ Paone N., ${ }^{7}$ Ryan, T., ${ }^{8}$ Steger, H., ${ }^{3}$ Tomasini, E.P., \\ ${ }^{9}$ Vanlanduit, S., ${ }^{10}$ Vignola, J.F. \\ 1. School of Mechanical, Electrical and Manufacturing Engineering, Loughborough University, UK. \\ 2. Department of Engineering Physics, University of Wisconsin - Madison, US \\ 3. Department of Industrial Engineering and Mathematical Sciences, Polytechnic University of \\ Marche, Italy \\ 4. Department of Mechanical Engineering, University of Bristol, UK \\ 5. Department of Physics, University of Antwerp, Belgium \\ 6. Department of Mechanical Engineering, Imperial College London, UK \\ 7. Department of Engineering, East Carolina University, Greenville, US \\ 8. Polytec GmbH, Waldbronn, Germany \\ 9. Department of Electromechanics, University of Antwerp, Belgium \\ 10. Department of Mechanical Engineering, Catholic University of America, Washington, DC, US
}

\begin{abstract}
In 1964, just a few years after the invention of the laser, a fluid velocity measurement based on the frequency shift of scattered light was made and the laser Doppler technique was born. This comprehensive review paper charts advances in the development and applications of laser Doppler vibrometry (LDV) since those first pioneering experiments. Consideration is first given to the challenges that continue to be posed by laser speckle. Scanning LDV is introduced and its significant influence in the field of experimental modal analysis described. Applications in structural health monitoring and MEMS serve to demonstrate LDV's applicability on structures of all sizes. Rotor vibrations and hearing are explored as examples of the classic applications. Applications in acoustics recognise the versatility of LDV as demonstrated by visualisation of sound fields. The paper concludes with thoughts on future developments, using examples of new multi-component and multichannel instruments.
\end{abstract}

KEYWORDS: laser vibrometry; LDV; laser Doppler; vibration measurement 


\section{Introduction}

Laser (Doppler) Vibrometry (LDV) has its origins in fluid velocity measurements reported by Yeh and Cummins [1] at Columbia University in 1964. Their seminal paper described measurement of "Doppler shifts in the Rayleigh scattered light at [flow] velocities as low as $0.007 \mathrm{~cm} / \mathrm{sec}$ " at a time when the laser was still in its infancy. Helium Neon $(\mathrm{HeNe})$ lasers were pioneered at Bell Telephone Laboratories, first in the infrared in 1960. The now familiar red HeNe laser used by Yeh and Cummins had been developed in 1962 and it remains prevalent in commercial laser Doppler instruments more than 50 years after those first experiments.

This review paper begins with an introduction to the principle of operation and a historical perspective on how the laser Doppler vibrometer (also generally abbreviated to LDV) has reached its current state of maturity. The effects of laser speckle have been and remain a concern in LDV and section 2 sets out the state-of-the art. Scanning LDV has been an extremely important development with wide application and this technique is considered before considering applications in structural heath monitoring, MEMS, rotating machinery, hearing and acoustics. The paper concludes with thoughts on future development.

Detection of the Doppler frequency shift that occurs when light is scattered by a moving surface is the basis of LDV [2]. This frequency shift is directly proportional to the surface velocity and so its detection enables convenient and non-contact measurement of vibration velocity. Detection is not entirely straightforward as the laser has a frequency typically 6 or 7 orders of magnitude higher than the Doppler shifts, which are typically in the low MHz range. Scattered light from the target has to be mixed interferometrically with a mutually coherent reference beam to produce a beat in the collected light intensity at the difference in frequency between the target and reference beams, i.e. down in the $\mathrm{MHz}$ range where demodulation is possible electronically. Such a configuration still leaves a directional ambiguity in the measurement because demodulation only identifies the modulus of the frequency shift. Early proposals achieved the necessary discrimination by introducing a known frequency pre-shift to the reference beam $[3,4,5]$. This modifies the frequency of the intensity beat to be less than or greater than the pre-shift frequency depending on the direction of the target velocity. Quadrature detection has also featured in commercial instrumentation as a means to discriminate direction but frequency shifting by Bragg cell reigns supreme as the preferred method in today's commercial instrumentation.

Flow measurements in fluids received much attention through the 1960s and 70s but it was not until the latter part of this period that Brian Moss and his team at the Atomic Energy Research Establishment at Harwell in the UK gave serious consideration to vibration measurements on solid surfaces using the laser Doppler technique [6]. Graham Bank and his team at the loudspeaker manufacturer Celestion of Ipswich in the UK added a scanning head to the Harwell instrument to 
provide a "3-D isometric view of the complete vibrating surfaces of the test object frozen in time" [7]. The Harwell instrument was developed by Ometron and became the first commercially available scanning LDV system. Volkswagen in Germany followed Celestion's example with its own scanning system [8]. A further significant innovation from this period was the introduction of a parallel beam instrument [9] for torsional vibration measurement on rotors. By the end of the 1980s, the growing maturity of LDV was evidenced by there being four prominent instrument suppliers. Polytec was an established supplier of laser-based test instruments whose Laser Vibrometers had built an excellent reputation through successful application in the emerging hard disk industry. Dantec's core business was in fluid flow measurements when they introduced their Laser Vibrometer. Ometron's instrument worked exceptionally well at low light levels and was unique in using quadrature detection for direction discrimination. Finally, Brüel \& Kjær, as a leading provider of traditional noise and vibration instrumentation, though, unlike their competitors, without any track record in laser-based instrumentation, released their first Laser Vibrometer. Polytec and Ometron were already offering scanning variants at this point and Polytec's range included a differential instrument.

A variety of optical configurations have been proposed in the scientific literature and by commercial providers. Fundamentally, however, instruments can be categorised as having a single probe beam for translational vibration measurement, or a pair of probe beams for differential vibration measurement. Multiple single beams or multiple pairs are of course possible. Scanning heads can be readily added to single beam instruments to automate the relocation of the beam in sequential point-to-point measurements across a structure. A pair of probe beams enables the classic differential measurement in which the relative velocity between two parts of a structure or device is determined. Configuration of the pair of beams as a V (cross-beams) is used for in-plane vibration measurement while a parallel beam arrangement enables angular vibration measurements including torsional vibrations. All instruments can be used for measurements on rotating and non-rotating structures. In all cases, orientation of the beam(s) determines the component of velocity measured with the corollary that it is the small but inevitable misalignments that usually determine measurement accuracy.

The first commercial instruments claimed particular advantages over traditional instrumentation, such as accelerometers or strain gauges, particular for measurements on hot, light, or rotating structures where traditional contacting instrumentation would change structural dynamics or be difficult to attach. Thin and soft structures could be added to the list but this would still neglect the special benefits now routinely exploited where high frequency operation, high spatial resolution or remote transducer operation is required. There are also several important limitations: limited access limits line of sight and makes measurement challenging, particularly on complicated 3D geometries, and measurement quality depends on the properties of the surface, which will be considered in the next section. 


\section{Laser Speckle and Pseudo-Vibration}

Despite 30 years or more of fairly relentless success for LDV, laser speckle has prevailed as its nemesis. When a coherent laser beam is incident on a surface that is optically rough, i.e. the surface roughness is large on the scale of the laser wavelength (from $633 \mathrm{~nm}$ for the red $\mathrm{HeNe}$ laser to 1500 $\mathrm{nm}$ for an infrared laser), the component wavelets of the scattered light become dephased. This condition is satisfied by many of the surfaces encountered in traditional engineering structures. The dephased, but still coherent, wavelets interfere constructively and destructively, thus resulting in a chaotic distribution in backscatter of high and low intensities, referred to as a "speckle pattern". Statistically the speckles have intensities with a negative exponential probability distribution, whilst their phases are uniformly distributed between 0 and $2 \pi$ [10]. Light collection is generally a summation over several speckles. Small adjustments in the position of the incident beam are sometimes necessary to avoid low signal amplitude resulting either from low overall backscattered intensity (from an uncooperative surface) or from an unfavourable summation of speckles over the photodetector(s). Such an unfavourable summation might be through a dominance of darker speckles or, more subtly, as a consequence of the phasor addition of each speckle in the collection. However, it is when speckles start to move or evolve in response to target motions (other than directly in line with the laser beam) that speckle effects can really become problematic.

Summation on the photodetector over a changing population of speckles has two important effects on the Doppler signal: amplitude modulation and phase modulation. The amplitude modulation can mean the varying signal amplitude drops occasionally to a very low level and so-called 'signal drop-outs' occur. This is a longstanding [11] and ongoing $[12,13]$ challenge. Even when adequate signal amplitude is maintained, however, dynamic changes in the sampled speckle pattern cause noise in the photodetector output phase which results in 'speckle noise' in the vibrometer output. Its precise origins have been explained [14] together with introduction of the more general term 'pseudovibration' [15].

The frequency content of pseudo-vibration is worthy of further consideration. Both signal drop-out (evident as spikes in the output) and pseudo-vibration (through changes in randomly phased speckles) contribute measurement noise across a broad frequency band. In particular, where the surface vibration (or whole body motion such as rotation) causing these effects is itself periodic, the resulting noise is pseudo-random with a spectrum comprising peaks at a fundamental frequency and higher order harmonics. These frequencies will generally be those of greatest interest making the noise difficult to distinguish from the genuine vibration. While decreasing the effects of signal drop-out is possible [12], particularly in the recent proposal of diversity reception [16], pseudo-vibration remains largely uncontrolled. To date the most successful mitigation has been to introduce a small side-to-side motion of the probe laser beam(s) sufficient to break the periodicity of the noise [17]. This spreads a slightly increased level of noise more evenly across the full spectrum, reducing spectral amplitudes at 
the important harmonic peaks at the expense of raised levels elsewhere in the spectrum. Manufacturers are yet to provide expected pseudo-vibration levels for their instruments but levels have been published in the literature in a format that can be widely applied by the user [18] and socalled 'pseudo-vibration sensitivities' have been quantified for a range of instruments and measurement scenarios [19]. A proper solution for pseudo-vibration, however, should be a priority for future research.

\section{Scanning Laser Doppler Vibrometry (SLDV) and Experimental Modal Analysis}

The potential for automating the relocation of a single laser beam using optical devices (typically a pair of orthogonally mounted galvanometer mirrors) to scan point-by-point across a structure was recognised at a relatively early stage [7] in the evolution of LDV. Particular applications emerged in the automotive [20] and aerospace [21] industries. While SLDV offers much to vibration testing generally, it is in the area of Experimental Modal Analysis (EMA) that SLDV has been so influential. EMA has been developed over the last 50 years [22] for the measurement of a structure's vibration, characterised in terms of its 'modal' properties which comprise two elements: temporal (natural frequencies and damping factors) and spatial (mode shapes). In essence, a modal test consists of applying and measuring an excitation force to a structure, and then measuring the response at various points. All the temporal properties can be extracted from the response measurement at a single point. The spatial properties, however, can only be extracted by measurement at many points and, when individual transducers are used, the number of measurement points is limited by cost and setup time, which compromises the resulting modal model. Using SLDV transformed this longstanding imbalance between the temporal and spatial modal properties. It would be impractical to attach $100 \mathrm{~s}$ or 1000s of individual transducers to capture a structure's mode shapes in detail but with an LDV it is possible to measure rapidly the response with a spatial resolution limited only by the laser beam diameter, typically a few tenths of a $\mathrm{mm}$, and the time required to capture each time record. Polynomial curve-fitting of such a comprehensive measurement data set can reveal the underlying order of the deflection shape [23] and inform the subsequent measurement density necessary to capture all the information in an optimal way.

Figures $1 \mathrm{a} \& \mathrm{~b}$ show mode shapes for the second string modes of a tennis racket [24]. These mode shapes demonstrate clearly one of LDV's main advantages - the ability to measure from very light structures, in this case the strings. The typical challenges of SLDV were all evident in these measurements including positioning the laser beam automatically on surfaces that are discontinuous or with local orientations that make light collection problematic, and suspending the test structure such that the laser beam remains at the required location during measurements. 

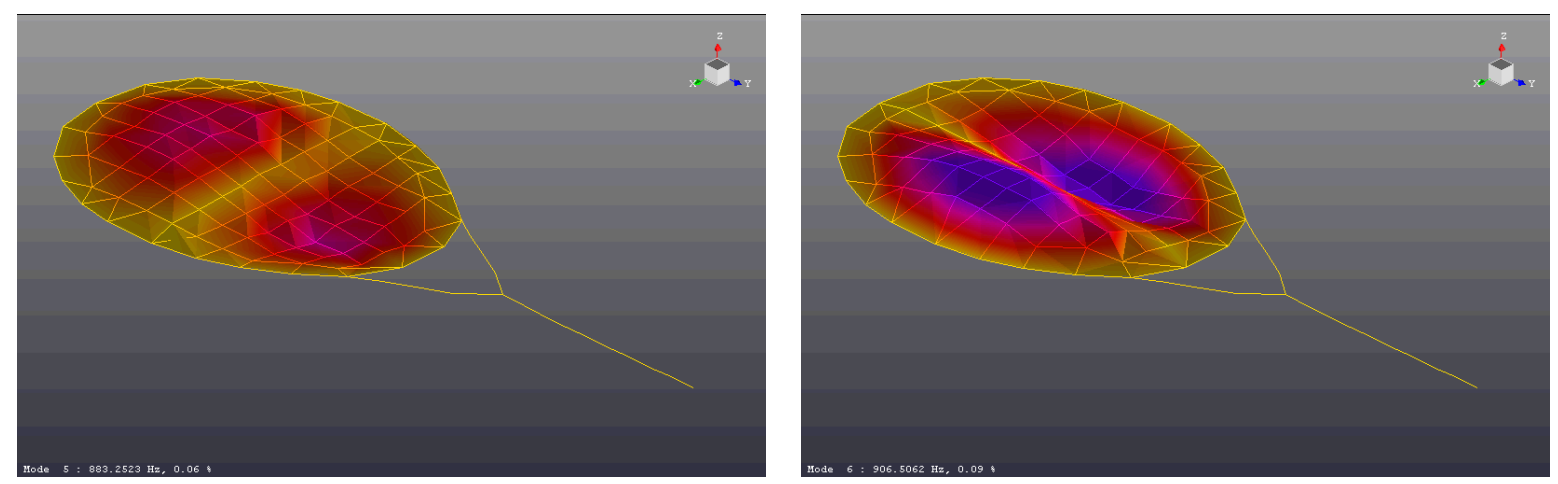

Figure 1: String mode shapes (second transverse mode pair) on a tennis racket measured by LDV.

Today's SLDV state-of-the-art offers automated, tri-axial vibration surveys on large, threedimensional structures (such as a vehicle) using three SLDVs each mounted on a robot arm, as shown in figure $2 \mathrm{a}$, or on microscopic structures with a scanning confocal microscope [25]. Figure $2 \mathrm{~b}$ shows a mode shape from a 3D SLDV analysis on a whole vehicle body combining 1000 measurements (0$500 \mathrm{~Hz}, 0.75 \mathrm{~Hz}$ resolution, 30 averages per point, measurement time 8 hours).
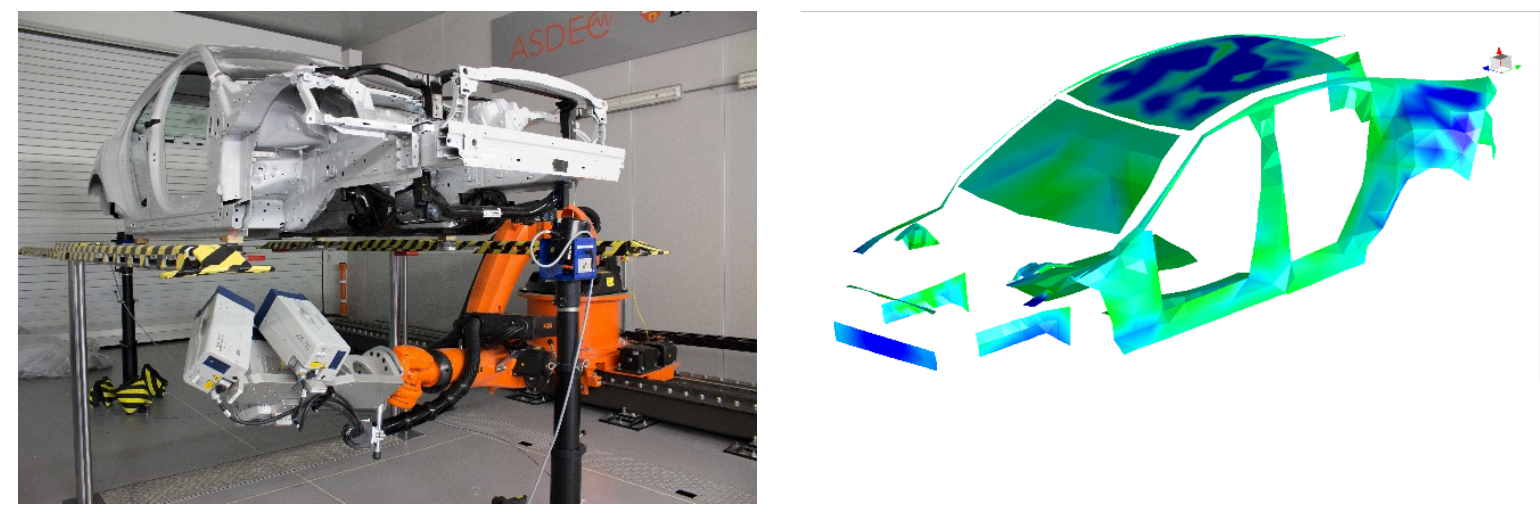

a)

b)

Figure 2: 3D SLDV on a whole vehicle body: a) instruments mounted on a robot arm, b) a typical vehicle mode shape. Courtesy of ASDEC http://asdec.co/ 


\section{LASER SCAN}

\section{x-scan $0.3 \mathrm{~Hz}$ y-scan $5 \mathrm{~Hz}$}

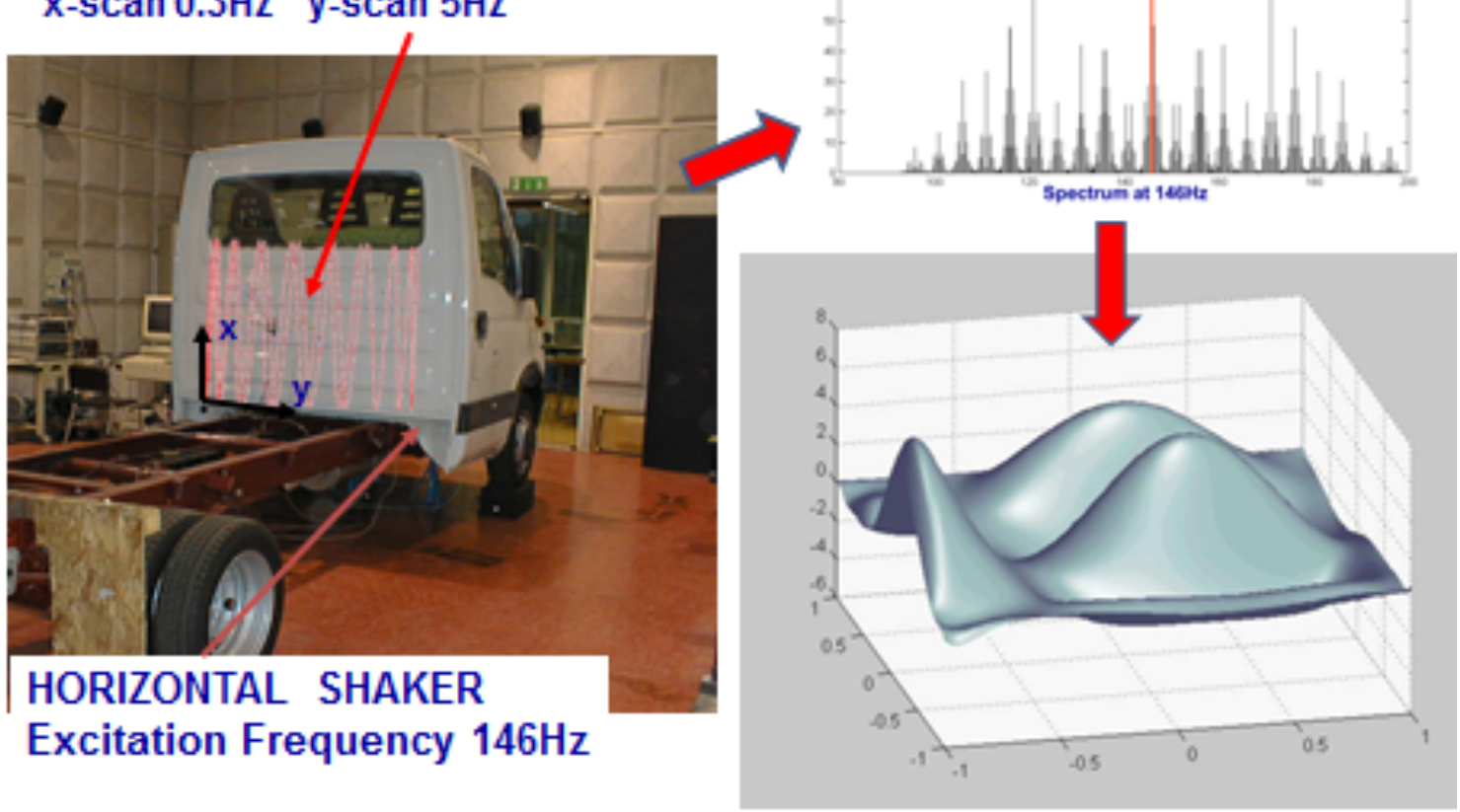

Figure 3: CSLDV on a vehicle cab showing scan pattern (left), measured velocity spectrum (top right) and ODS reconstructed from polynomial fit (bottom right).

In traditional SLDV, the laser beam dwells at each measurement point for a duration set by the spectral resolution required. Measurement at many points can be accelerated by continuous-scan laser Doppler vibrometry (CSLDV), where the laser beam scans continuously along a defined path across a structure at specifically selected scan frequencies. Small-scale circular and conical scans have been used [23] to measure multiple vibration components simultaneously at a point. Using these principles, a dedicated scanning head has enabled all six degrees of freedom to be measured at a point on a structure in a single measurement [26].

For modal testing, the significance of CSLDV is that it replaces the exclusively temporal view with much greater emphasis on the spatial properties of a structure's modal model. This can greatly accelerate modal testing but requires specialised processing algorithms because the measurement point is constantly moving. The first measurements were from a line scan on a cantilever beam [27] (using a cross-beam LDV partly because of a mistaken view about the unsuitability of a single beam LDV), while both line and area scanning methods have since been developed using sinusoidal $[23,28$, 29], impact [30], and pseudo-random excitation [31]. Figure 3 shows an area scan on a vehicle panel with single frequency excitation. Different horizontal and vertical scan frequencies produce the spectrum shown, which comprises harmonic sidebands, centred about the excitation frequency and 
spaced by the scan frequencies. The Fourier components are related to the coefficients in the polynomial description of the deflection pattern. A more complicated shape requires higher order polynomial coefficients for accurate reconstruction and so the precision of CSLDV is set by the number of harmonics that stand out above the noise floor in the measured spectrum. This can be limited by signal drop-outs, primarily related to surface quality, and speckle noise, especially at higher scan speeds [32].

CSLDV data can also be processed by the "lifting" approach [33], in which the responses from each incremental location along the laser path are grouped together and treated as if they are the outputs from an array of sensors fixed at these locations, except that the responses are not measured simultaneously. The time increment in these reconstructed responses is equal to the scan period and aliasing can occur. In a study using the lifting approach to extract the natural frequencies and massnormalized mode shapes of a free-free beam under impact excitation [33], the need for the scan frequency to be larger than twice the maximum frequency of interest was demonstrated. Where this is not possible, the scan frequency can be chosen to ensure that the modes do not overlap after being aliased to the band of half of the scan frequency. The harmonic transfer function (HTF) concept [34] can be used with CSLDV to address output only modal analysis, where the input is not measured but can be assumed to be broadband and random. This approach was successfully applied to CSLDV measurements of a parked wind turbine excited by a light wind [35].

\section{Applications}

The honour of having the first published application paper goes to Davis and Kulczyk and their work on turbine blades published in Nature in 1969 [36]. Further applications were scarce for over a decade then work in loudspeakers [7] and hearing [37, 38] appeared, followed by hard disk drive measurements $[39,40]$ and the first rotor applications [41, 42], including engine torsional vibrations [43]. These were accompanied by less predictable studies on the fiddler crab [44] and plants [45]. Today, LDV is well established as an effective alternative to traditional contacting vibration transducers in diverse applications.

In this section, a selection of those applications is presented. This is no simple task. To do full justice to a technique that has been applied so widely not only across the many sectors of mechanical, electrical and civil engineering, and their underpinning science, but also in areas such as medieval fresco condition [46], fruit ripeness [47] and infant respiratory health [48] is quite a challenge. Nonetheless, the authors have selected five broad areas to showcase the capability of LDV.

The first section on structural health monitoring and the second on MEMS demonstrate LDV's applicability on structures of all sizes, from the very large to the very small. The third section on rotor vibrations covers one of the classic applications quoted in the early years of commercial 
instrumentation and in which remote, non-contact operation and insensitivity to target shape (for rough surfaces) prove especially valuable operational features. The fourth section on hearing exemplifies activity in the areas of biological and biomedical science and is another of the classic applications. Finally, the fifth section on acoustics recognises not only the important relationship between structural vibration and noise radiation but also the versatility of LDV which can even be used to visualise sound fields

\subsection{Structural Health Monitoring}

LDV has proved to be an effective diagnostic tool in damage detection on structures because of its ability to make non-contact measurement over a dense grid of points. Composite materials have attracted most attention but the same principles have been applied to assessing detachment of mediaeval frescoes [46] and the detection of landmines [49].

The location of defects has been considered extensively [50-55] by analysing wave propagation, modal response or operational deflection shapes (ODS). While the exact location of a defect has been found in these studies, test structures have been relatively simple. Techniques such as 3D-SLDV and its use for strain measurements [56] may hold the key to locating defects on more complex structures, particularly if the goal is to develop a near real-time inspection technique for instant detection of the onset of damage. ODS measurements using CSLDV are well suited to real-time inspection because of the speed with which data can be acquired. Choice of excitation location is an important factor that can make the ODS more sensitive to defects [57]. For vibration-induced fatigue on a flat composite plate $(100 \times 300 \mathrm{~mm})$, it was observed that some samples exhibited changes in ODS during endurance trials, as shown in figure 4 for the first bending mode [58].
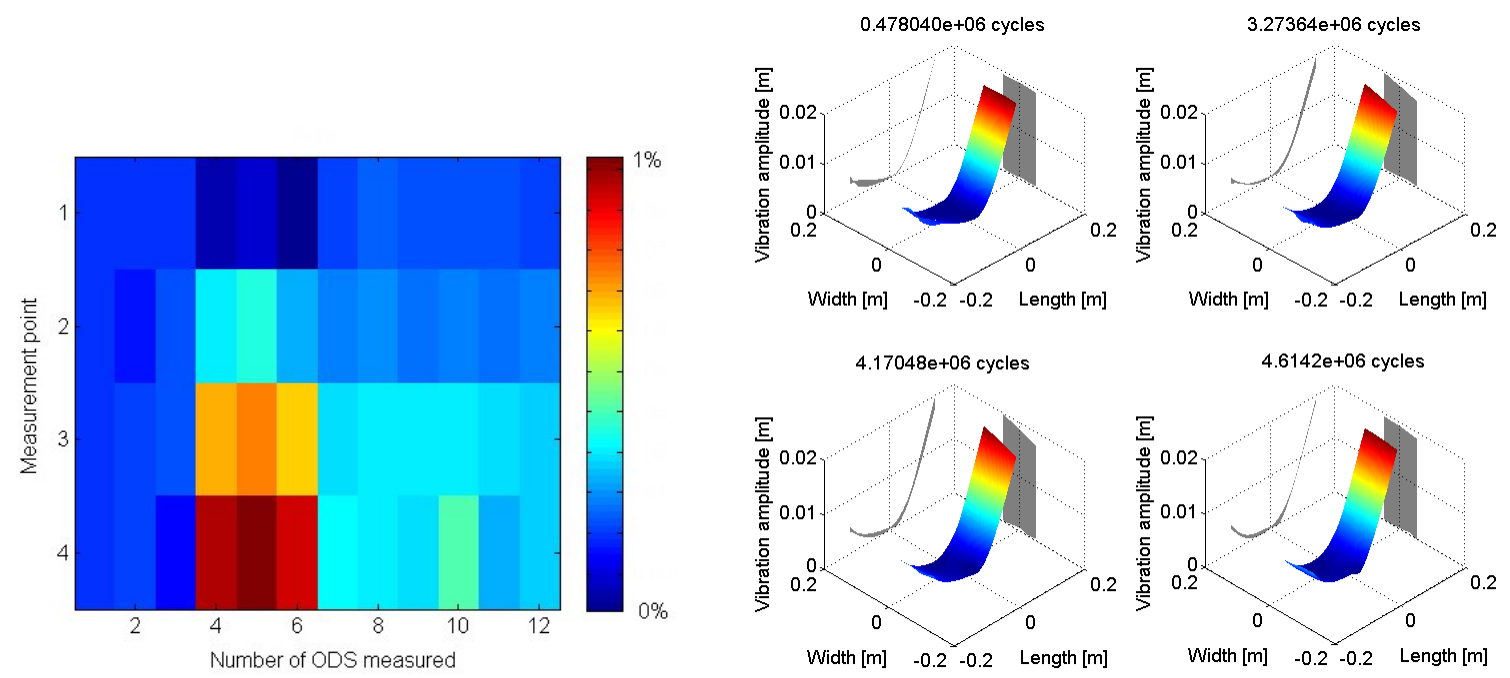

Figure 4: a) Change of ODS over 12 measurements and b) example of 4 full ODSs 


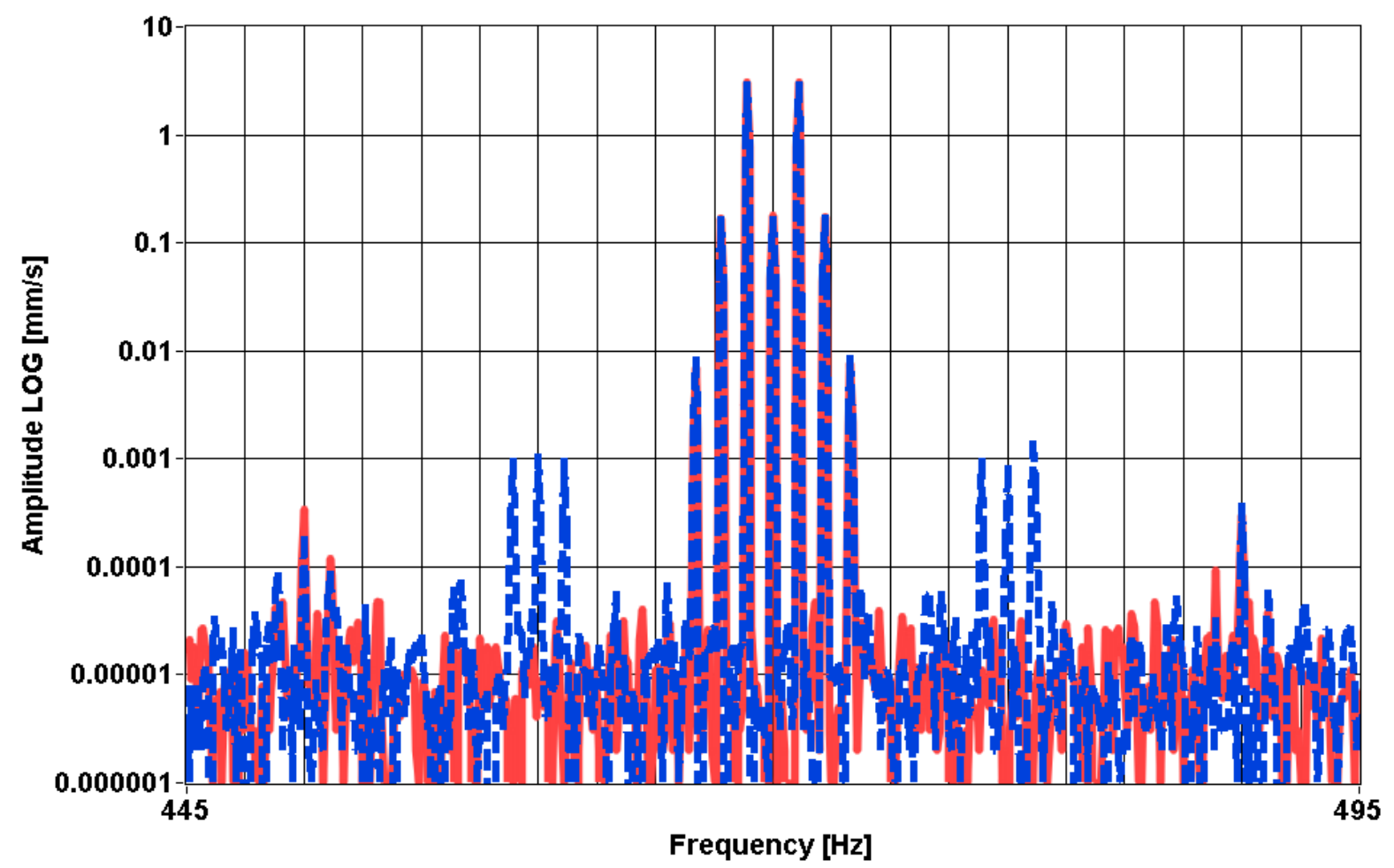

Figure 5: Appearance of additional sidebands as a consequence of damage. Blue dashed line is the damaged case and the undamaged case is the solid red line

The ODS analysis is based on spectral sidebands, which characterise all CSLDV measurements and are the signature of the specific ODS. Monitoring sidebands should therefore be sufficient to diagnose an emerging defect without the need to complete the ODS post-processing. Figure 5 shows from simulation [58] how additional spectral sidebands appear as damage grows. Step-sine excitation is suited to finding the frequency range most affected by the damage.

\subsection{MEMS}

In Micro-ElectroMechanical Systems (MEMS), semiconductor fabrication technology is used to create systems with coupled mechanical and electronic properties. These can include small-scale motors and fluid pumps for applications as varied as inkjet printers or lab-on-a-chip technology. In dynamic MEMS systems, a part of the system is driven to vibrate, often at resonance, with applications including surface acoustic devices, micro-mirror arrays and sensors. Here, LDV's distinct advantages over microscopy based techniques include three-dimensional measurements $[59,60]$ of picometre displacements, over a wide area [61] and at $\mathrm{GHz}$ frequencies. 
For such a challenging application, LDV is not without issues. These include laser spot size, laser heating, specular reflections, optical access due to complex geometries and heat dissipation issues, as well as the need to look through a window into a controlled test environment.

In macro-scale structures, the laser beam diameter is generally negligible but this is not the case on micro-structures. Practically, the LDV probe beam cannot be smaller than about half the optical wavelength, typically $633 \mathrm{~nm}$. To satisfy the spatial Nyquist limit requires at least two measurements per structural wavelength, placing a limit on the measureable structural wavelength that is approximately equal to the optical wavelength. However, resonant devices are often operated in vacuum to reach high $Q$ values [62]. In this case, the converging probe beam passes through a glass window which introduces spherical aberration that results in larger beam diameters and so a lower frequency limit for modal analysis.

The laser power, typically $1 \mathrm{~mW}$, has a measurable thermal effect on the smallest scale systems as a consequence of the high fraction of the incident laser light absorbed by silicon and of heat transfer rates for small slender geometries. This can cause devices with a characteristic cross-section dimension of $1 \mu \mathrm{m}$ or smaller to have a temperature differential of $10^{\circ} \mathrm{C}$ or more along their length. This may result in significant shifts in resonance frequencies or dimensional expansion. As a result, commercial micro-LDV systems have facility to dim the probe beam.
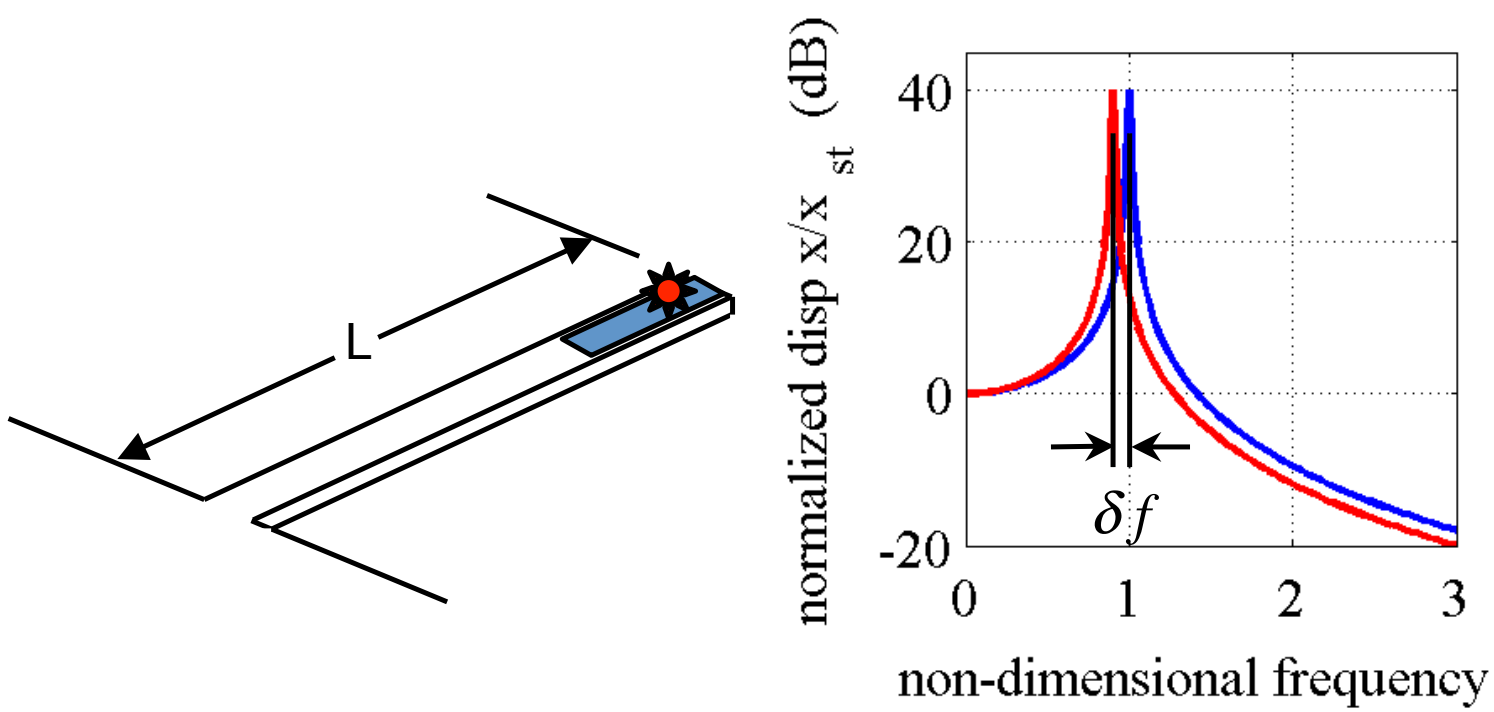

Figure 6: A mass sensing cantilever (left) uses a functionalized tip to capture a target molecule. The added mass shifts the resonance frequency (right) which can be related to the added mass.

Figure 6 shows an example of a MEMS device using resonant cantilevers for attogram mass detection [63]. The capture of a target molecule results in a measurable shift in resonant frequency which can then be related back to the added mass. Figure 7 shows a micro-LDV scan of a cantilever pair. In these measurements, scanning is achieved by placing the specimen on a computer-controlled 
translation stage, rather than by scanning the laser beam itself. The cantilevers are $0.5 \mathrm{~mm}$ in length, $90 \mu \mathrm{m}$ wide and the pixel size is $8 \times 21 \mu \mathrm{m}$. These data reveal a slight twist in the fundamental mode $(25,320 \mathrm{~Hz})$ and a higher twisting mode in the right cantilever at $40,670 \mathrm{~Hz}$ and illustrate the unrivalled capability of scanning micro-LDV for MEMS applications.

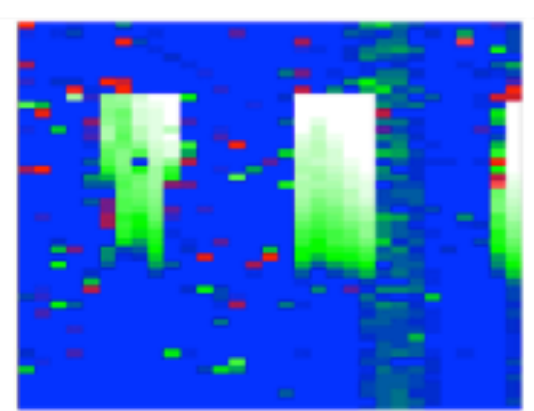

$25320 \mathrm{~Hz}$

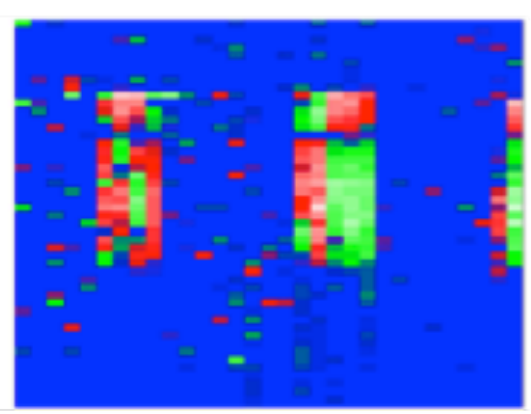

$40670 \mathrm{~Hz}$

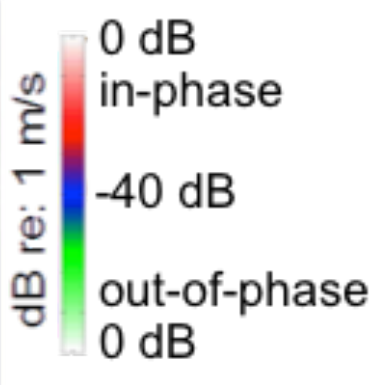

$0 \mathrm{~dB}$

Figure 7: A micro-LDV scan of a pair of micro-cantilevers. The colours differentiate motion that is inphase (red) and out-of-phase (green) with the excitation.

\subsection{Rotating machinery}

Vibration has long been acknowledged as the most effective measure of the condition of rotating machines and LDV offers direct measurement of the favoured parameter (i.e. velocity) with dynamic and frequency ranges at least matching and generally exceeding those offered by piezo-electric accelerometers. LDV applications for axial vibration measurement directly from rotating blades date back over 40 years [36] and interest in similar applications continues today using both stationary [64] and scanning [65] laser beams, respectively known as Eulerian and Lagrangian approaches. When scan frequency and path is synchronised with the whole body motion of a target, a measurement can be performed in which the probe laser beam tracks a particular point on the target and this is the subject of the first part of this section. Torsional vibration measurement with a parallel beam configuration is an established and successful use of LDV with applications including torsional damper health [17], electric machines [66], railway wheel-sets [67], backlash in gears [68] and crankshaft bending and driveshaft vibration [69]. Measurement is facilitated by inherent insensitivity to translational vibrations. Radial and bending (pitch / yaw) vibration measurements have also been successfully demonstrated [69] but there are important practical considerations for the user and these are dealt with in the second part of this section.

\subsubsection{Tracking and Self-Tracking LDV}

The technique of Tracking Laser Doppler Vibrometer (TLDV) was developed in the 1990s as an alternative to a traditional de-rotator and as a way to take advantage of the SLDV. Its first reported 
application was on a propeller rotating in water [70], followed by analysis of measurement uncertainty [71]. Figure 8 shows the set-up in which the orthogonal scanning mirrors within the SLDV head are controlled to track a fixed point on a rotating target. As an open-loop control system, knowledge of the scanning head and target geometries is required as well as definition of the point to be tracked. Most importantly, an encoder is required from which the angular positions of the two scanning mirrors can be computed such that the laser beam follows the chosen point of interest on the target.

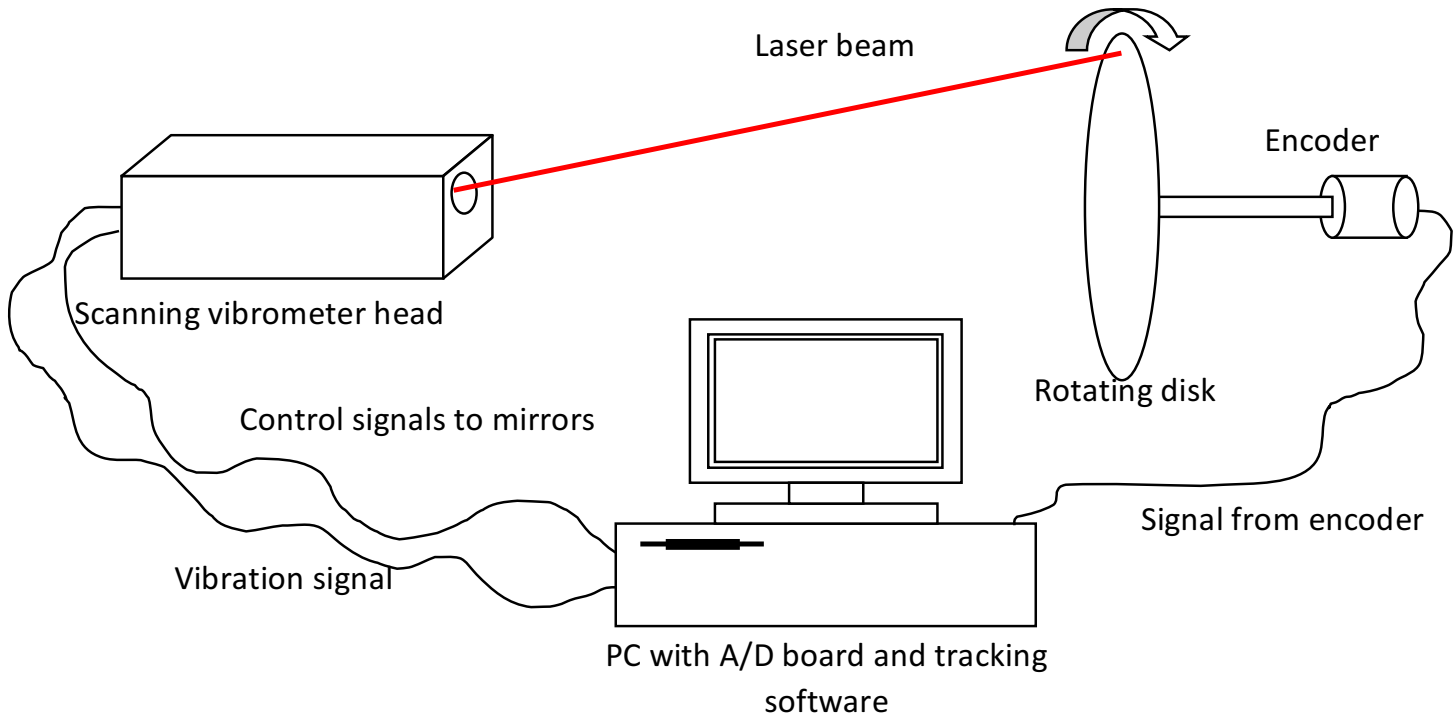

Figure 8: Schematic diagram of the first TLDV system

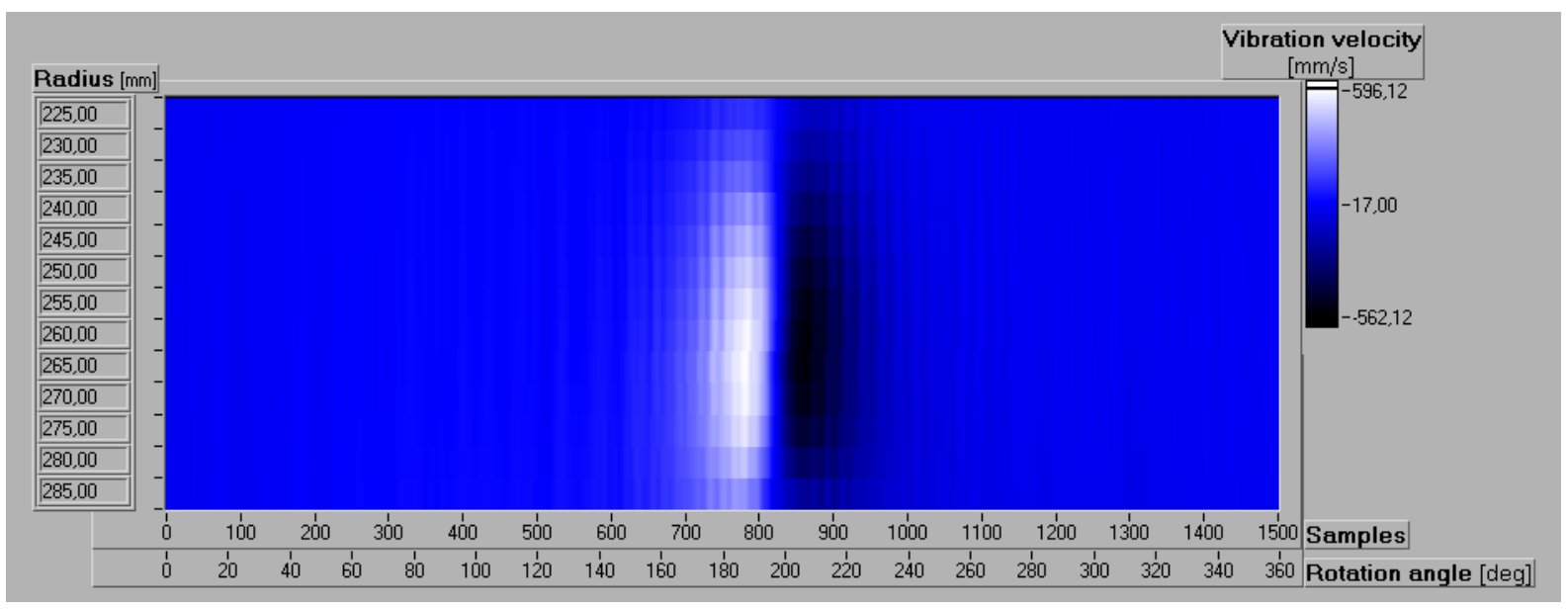

Figure 9: TLDV map on a tyre sidewall

Further TLDV applications include rolling tyres and timing belts (partial track) [72] and on targets with vibrating parts fixed to a component with a large whole body motion such as windscreen wipers $[72,73]$. Figure 9 shows a vibration map for a rolling tyre wall as a function of radius, quantifying the extent of the bulge and recovery in the tyre wall as the tracked point approaches and leaves the 
contact point on the roller. The attractions of tracking and scanning simultaneously on a rotor have also been explored $[74,75]$ in order to measure operational deflection shapes.

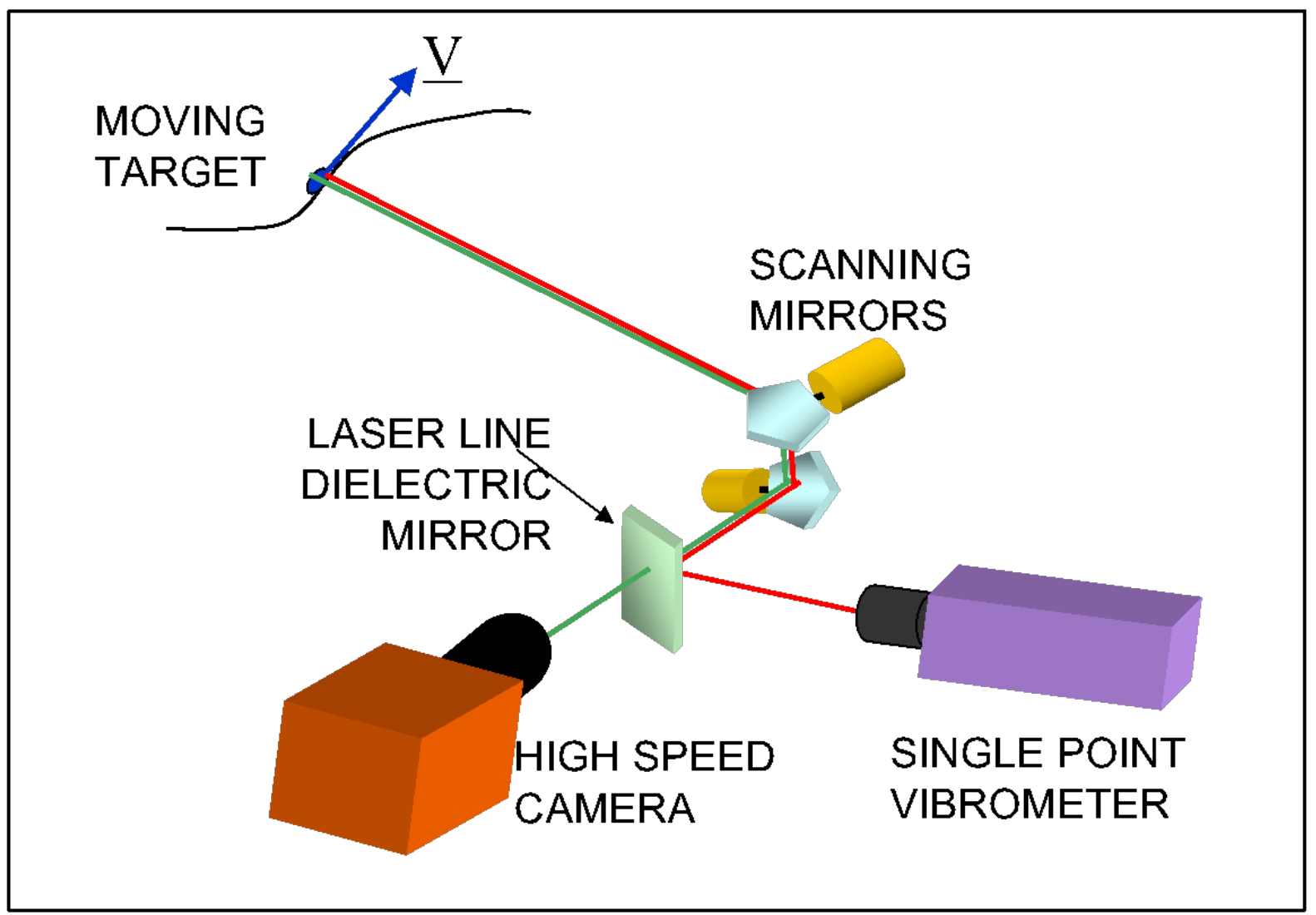

Figure 10: Layout of image Tracking LDV

An image-based system (iTLDV) system [76] is a natural evolution of TLDV with closed-loop control using position signals for the target obtained from a CCD camera and a real-time image processing algorithm. As shown in figure 10, a camera is aligned with the optical axis of the LDV system and its image is observed through the same mirrors used for the LDV scanning head. The instantaneous position of the target point relative to that of the laser beam is used as the error for the feedback signal, overcoming limitations of the open-loop TLDV system including the need for geometrical information and the encoder.

The response time of the galvanometer mirrors used in all of these TLDV systems places a limit on the scan frequency and scan radius attainable. For this reason, schemes in which oscillatory mirror motions are replaced by whole body rotations of optical devices have been considered. These include self-tracking systems [77], an arrangement incorporating wedge prisms [78], and a commercial system using a rotating Dove Prism [79], which is well known in optics as an image rotator. A framework suitable for modelling tracking and self-tracking systems with a detailed quantitative analysis of uncertainty related to geometry and inevitable misalignments has been developed [80]. 


\subsubsection{Radial and bending (pitch / yaw) vibration}

Radial vibration measurements are of particular interest in automotive powertrain [69], hard disks and their drive spindles [81, 82], and tool condition monitoring in turning [83] and milling [84]. Early attempts to use LDV for radial vibration measurements on rotors, however, identified a significant cross-sensitivity to the radial vibration component perpendicular to the radial component it is intended to measure as a consequence of oscillation in the position of the rotor centre relative to the fixed line of incidence of the beam [85]. Unavoidable detection of the velocity component due to the rotation itself results in a cross-sensitivity that cannot be resolved by laser beam orientation alone but which requires a dedicated resolution procedure [86]. This requires simultaneous orthogonal vibration measurements and a rotation speed measurement, as shown in figure 11, followed by post-processing.

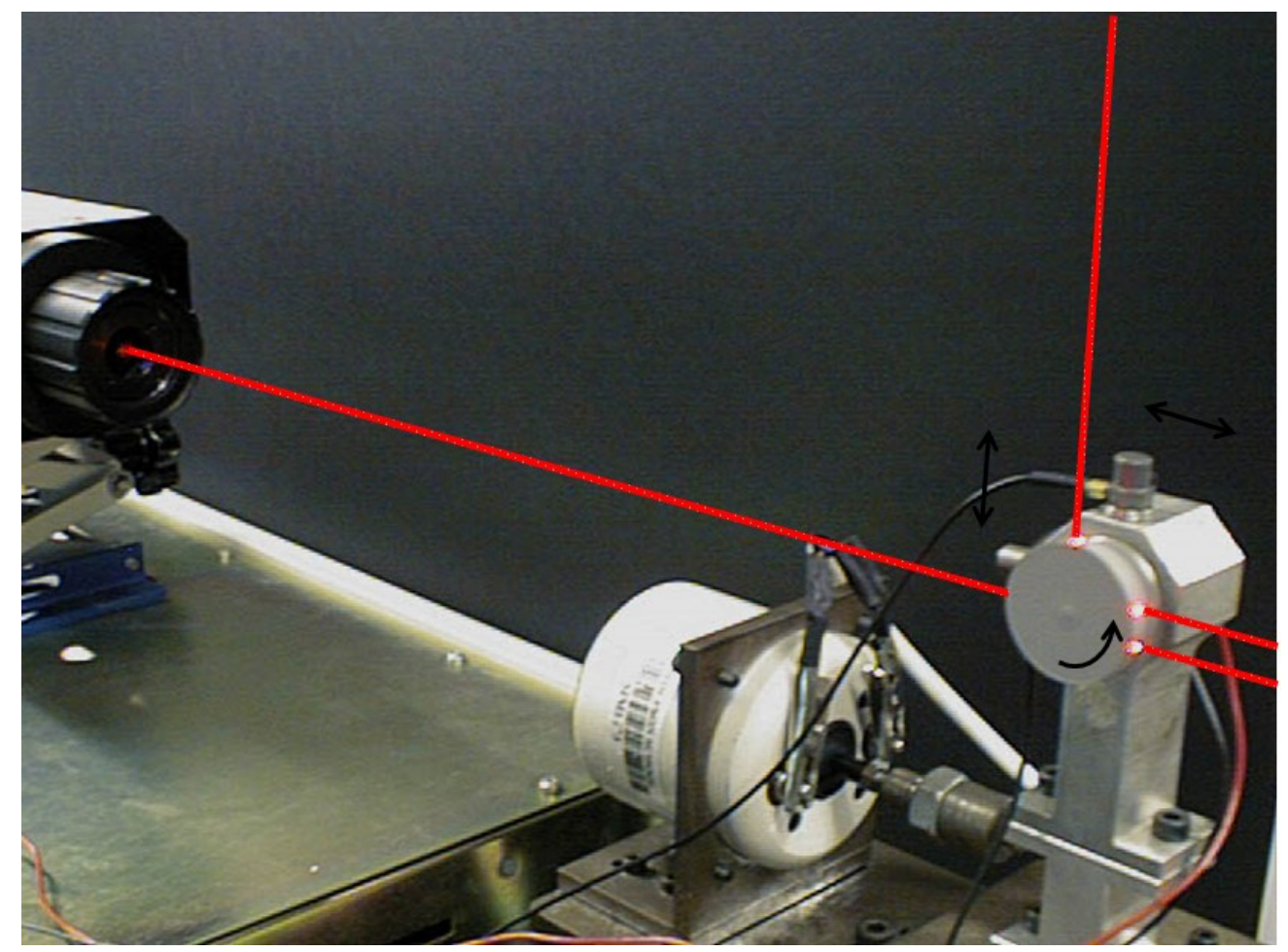

Figure 11: Laboratory tests in which orthogonal single laser beams measure orthogonal radial vibration components and a parallel beam instrument measures rotation speed

These cross-sensitivity studies had concentrated on rotating surfaces treated with retro-reflective tape (Scotchlite high-gain sheeting type 7610), a common surface treatment intended to maximise the intensity of light scattered back towards the instrument's collecting optics. In a separate study [87], radial vibration measurements on a painted rotor confirmed the presence of this cross-sensitivity but measurements made on a polished rotor (Ra $20 \mathrm{~nm}$ ) showed no such cross-sensitivity, emphasising an urgent need to resolve this contradiction. Important practical recommendations have now been made [88] about the roughness ranges in which accurate measurements can be made. For surface roughness 
below $10 \mathrm{~nm}$, radial vibration measurement is possible on a circular cross-section rotor without postprocessing provided the displacement amplitude does not exceed approximately half of the beam diameter. At roughness up to $50 \mathrm{~nm}$, measurement is still possible without post-processing but only up to around $10 \%$ beam diameter. For rougher surfaces or for non-circular cross-sections, retro-reflective surface treatment must be used and post-processing applied, though the synchronous component cannot be resolved. This is a fundamental limitation of the measurement and not a deficiency of the post-processing technique.

Similar issues of cross-sensitivity are encountered when a pair of parallel beam instruments is deployed for bending (pitch / yaw) measurements [89] i.e. sensitivity in a pitch measurement to yaw motion and vice-versa for rough rotors but no cross-sensitivity when rotors are polished-circular. Two preferred measurement configurations exist: from the side of a polished-circular rotor and from the end face of a (rough) rotor coated in retro-reflective tape. Rotors with surface roughness up to $50 \mathrm{~nm}$ satisfy the 'polished' condition provided the vibration displacement at the rotor surface does not exceed $20 \%$ beam diameter. For surfaces with roughness of $10 \mathrm{~nm}$ this can be extended to $50 \%$. For rough rotor measurements and those taken from the end face of a polished rotor, post-processing is required to resolve the inherent cross-sensitivity.

The significant difference in behaviour between the rough and polished-circular rotors is associated with the way in which the polished-circular rotor preferentially reflects light that passes through the rotor centre line back to the collecting optics of the instrument. In this way, the collected intensity is dominated by wavelets of the laser beam that do not sense a component of the rotor tangential velocity and so do not exhibit the problematic cross-sensitivity. A corollary of this is when pitch / yaw measurements are taken from the polished end-face of a rotor. In such a case, there is no surface shape to cause the required preferential reflection and so cross-sensitivity is encountered despite the surface being polished.

\subsection{Hearing}

The eardrum and the three ossicles of the mammalian middle ear act as an acoustic impedance match between air and the fluid-filled inner ear, from where electrical impulses are sent to the brain. At the threshold of hearing sensation, the eardrum vibration displacement is less than $0.1 \mathrm{~nm}$. The introduction of heterodyne Doppler vibrometry [37, 90], long before commercial systems were available, was a major breakthrough in understanding this complicated and impressive mechanical system. Today, commercial LDVs are the instruments of choice for an ever-increasing range of research studies in hearing mechanics. LDV was used to investigate the motions of the eardrum and the ossicles in a single axis [91] and in 3D [92]. The high linearity of the technique made it possible to determine small nonlinearities within the response of the system [93, 94]. 


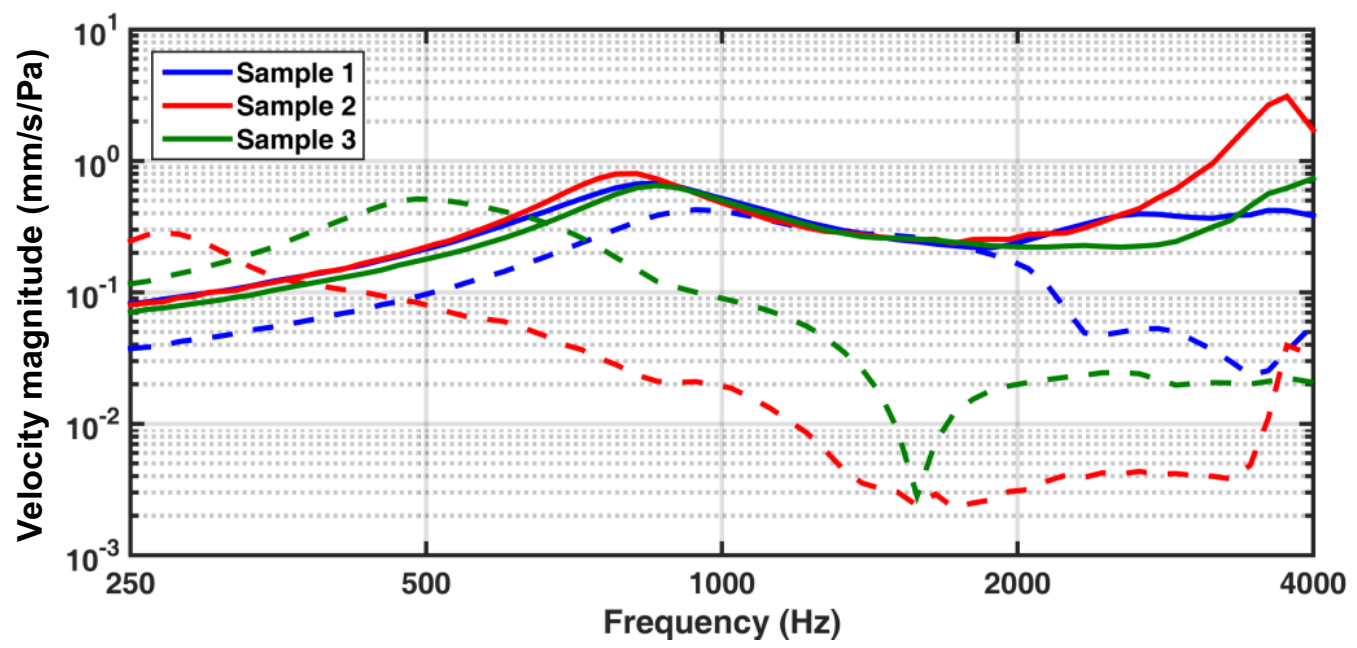

Figure 12: Normalized velocity of the stapes footplate in 3 sample human cadaver ears. Solid lines for an intact ossicular chain, dashed lines with a prosthesis that directly couples the eardrum to the stapes ossicle.

In clinical applications, from the research laboratory to the operating theatre, studies have been made of ossicular prostheses [95] and active middle ear implants [96, 97]. For example, LDV measurement combined with finite element modelling has revealed how the columella (the single ossicle connecting the eardrum directly to the inner ear in birds) transfers sound energy almost as efficiently as the threeossicle mammalian ear. Figure 12 shows responses, with acoustic excitation of the eardrum, of the human ear for three human cadaver samples. The solid lines are for an intact ossicular chain, while the dashed lines are with an implanted prosthesis which, after fracturing the ossicular chain, directly couples the eardrum to the stapes ossicle to resemble a columella. At a sound pressure level of $94 \mathrm{~dB}$, oscillation amplitudes are around 0.1 to $1 \mathrm{~mm} / \mathrm{s}$ and LDV is indispensable for measurement of such small velocities with good precision. These fundamental studies are intended to advance the design of human ossicular prostheses [98].

\subsection{Acoustics}

Non-contact measurements on lightweight structures with LDV has been particularly important in the field of acoustics and this was recognised at an early stage by loudspeaker designers [7, 99]. Similar applications include the characterisation of microphones [100] and ultrasound sensors [101]. For the same reason, LDV-based analyses of musical instruments have been numerous [102] and included violins [103], guitars [104] and percussion instruments [105, 106].

Calculation of radiated sound pressures is another important application area, enabled by the convenience of LDV for vibration measurements on a structure with high spatial resolution [107]. Successful applications have been found in automotive [108], aerospace [109], machine design [110] 
and construction [111] systems.

The examples in this section so far have been measurements of structural vibration to understand acoustic phenomena rather than direct acoustic measurements. Direct measurement of acoustic velocity is possible with micro-particles seeded in a fluid [112] or on an acoustically transparent membrane [113]. There is, of course, a small but unavoidable effect on the sound field itself when using seeding particles or membranes. This is not the case in refracto-vibrometry in which the change in refractive index of a fluid due to sound pressure is measured in a particularly innovative application of LDV. The resulting optical path variation is detectable as a Doppler shift [114] and sound waves can be visualized in air [115] or underwater [116].

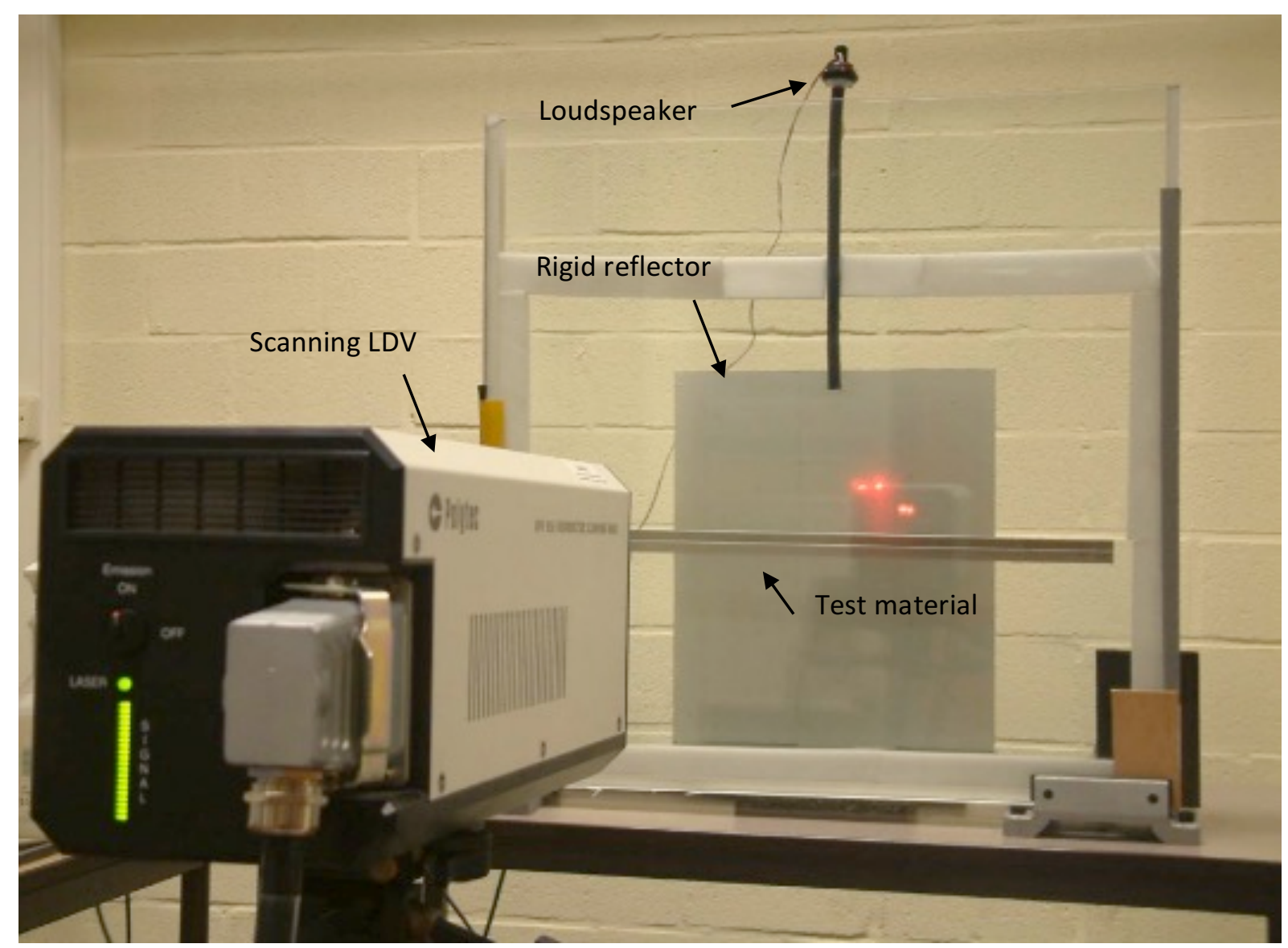

Figure 13: SLDV measurement of sound field between glass plates

The major limitation of refracto-vibrometry is that measurement is based on an integration along the path of the laser rather than from a point. Using 3D tomographic reconstruction techniques this projection can be demodulated to obtain the full 3D pressure field [117]. Refracto-vibrometry has been applied to determination of the acoustic absorption of materials [118]. This determination is possible in a glass tube terminated with the test material or between two parallel plates terminated by the test material as shown in figure 13 . Sound waves radiated from the end of a tube connected to a 
loudspeaker are reflected from the test material for which the acoustic absorption coefficient is to be measured. The SLDV is directed at a rigid reflector such that the laser beam traverses the sound field between the two glass plates twice. Figure 14 shows the sound fields for a rigid reflection (steel beam) and from a melamine foam. Reflection coefficients of $99 \%$ and $3 \%$ respectively were obtained.

Unlike the one-dimensional measurement in a tube, 2D measurement between the glass plates allows investigation of the acoustic absorption coefficient for non-normal incidence.
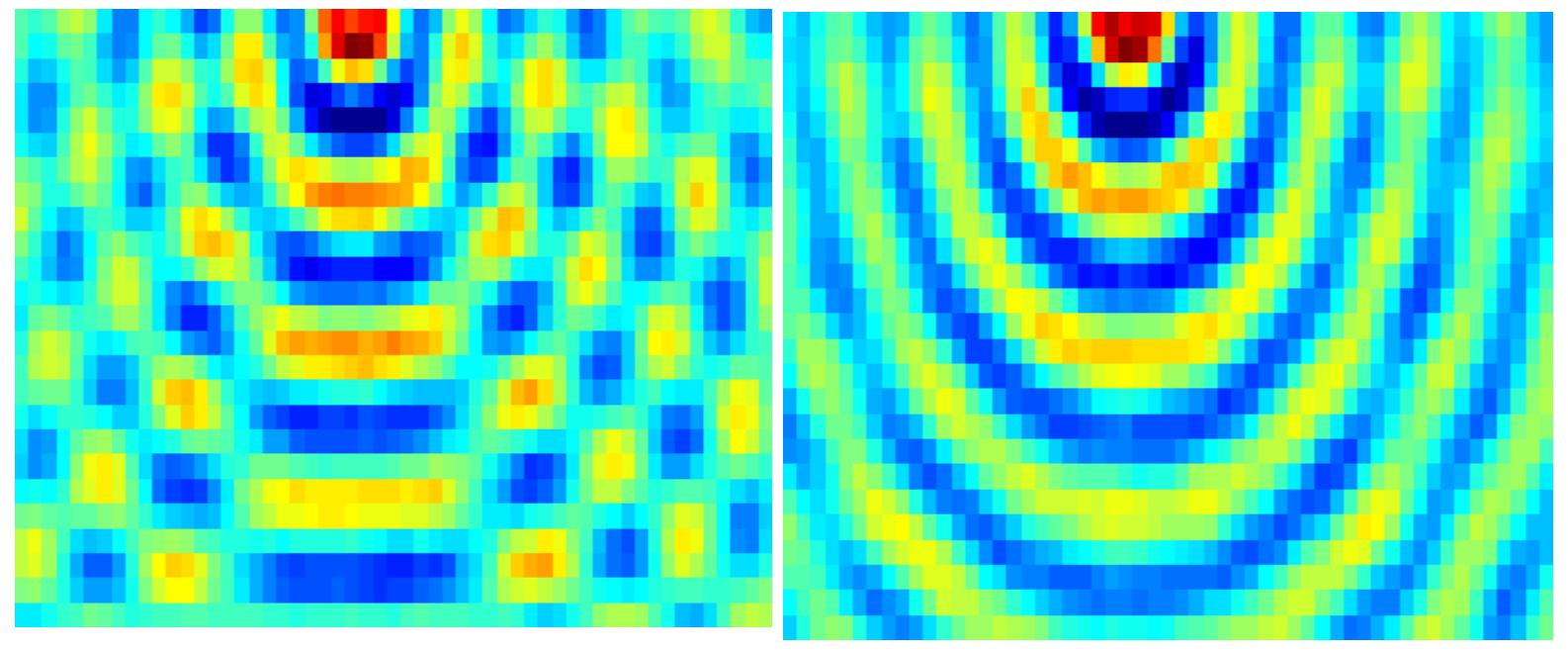

Figure 14: Sound fields in-between the parallel glass plates a) rigid reflection (steel beam) b) from melamine foam of $4 \mathrm{~cm}$ thickness.

\section{Future Developments}

Advances in measurement science and technology including the ability to capture large volumes of data at high rates, in combination with the computational capacity for subsequent analysis, are driving higher and higher expectations from measured data. In the case of LDV, this manifests itself in the users' desire for high resolution (spatial and temporal), multi-component, multi-channel measurements and the technology providers' efforts to satisfy their appetite. In this section, two examples are presented. The first is concerned with the provision of 3D vibration data for MEMS devices and the second looks at multi-channel capability for transient measurements.

\subsection{D measurements on MEMS devices}

LDV's status as the premier technique for analysis of MEMS devices was established in section 4.2. For some time, 3D measurements have been provided by combining an out-of-plane LDV measurement with in-plane vibration measurements using video microscopy. Superior measurement of all three vibration components is desirable but simultaneous measurements with separate optical 
heads, while suited to measurements on larger objects with scattering surfaces, is problematic with reflective microstructures. Optical crosstalk would be a particular concern because the three beams would have to be positioned so closely together to achieve the required spatial resolution, typically microns. The novel solution proposed is shown in figure 15.

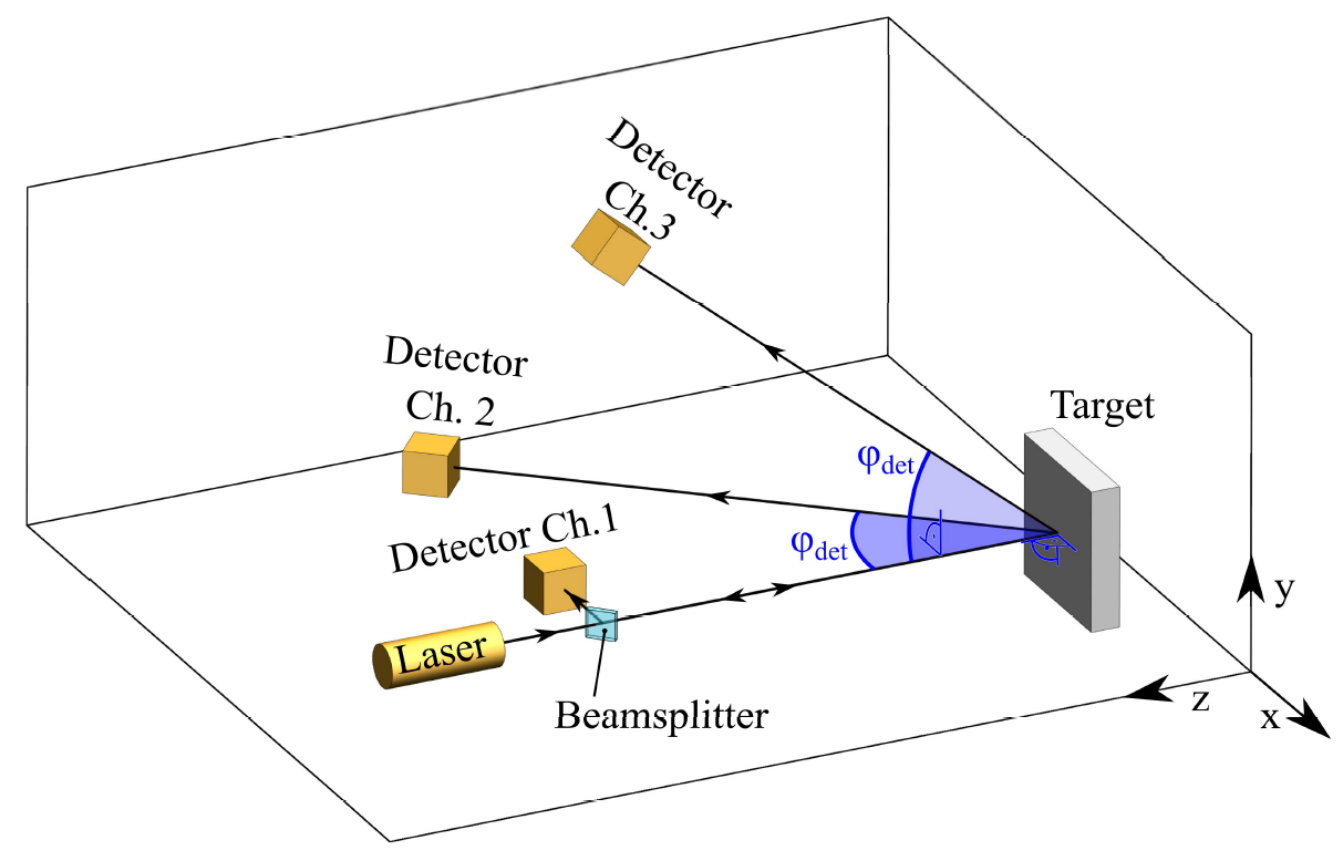

Figure 15: Optical setup for 3D microscope based LDV

Rather than using separate optical heads, the configuration incorporates a single probe beam and simultaneous light collection in three directions. Channel 1 is only sensitive to out-of-plane motion (zdirection) while channels 2 and 3 each collect light at an angle $\varphi_{\text {det }}$ to the z-axis. In the general setup in figure 15, the channel 2 collection direction sits in the $(\mathrm{x}, \mathrm{z})$ plane while that for channel 3 sits in the $(y, z)$ plane to ensure equal sensitivity in both directions. The collection directions of the optimised geometry balance the competing requirements of sensitivity to in-plane vibration and collection of sufficient light intensity. This results in a beam diameter below $3.5 \mu \mathrm{m}$, depth of focus of $\pm 10 \mu \mathrm{m}$ and a working distance of $36.7 \mathrm{~mm}$. Laser beam intensity can varied between approximately $15 \mu \mathrm{W}$ (to avoid any heating effect) and $5 \mathrm{~mW}$ (to reduce measurement noise). Scanning is again achieved by placing the specimen on a translation stage. Figure 16 indicates the importance of 3D measurement on a PZT MEMS cantilever in a higher order bending mode with significant in-plane motion. 


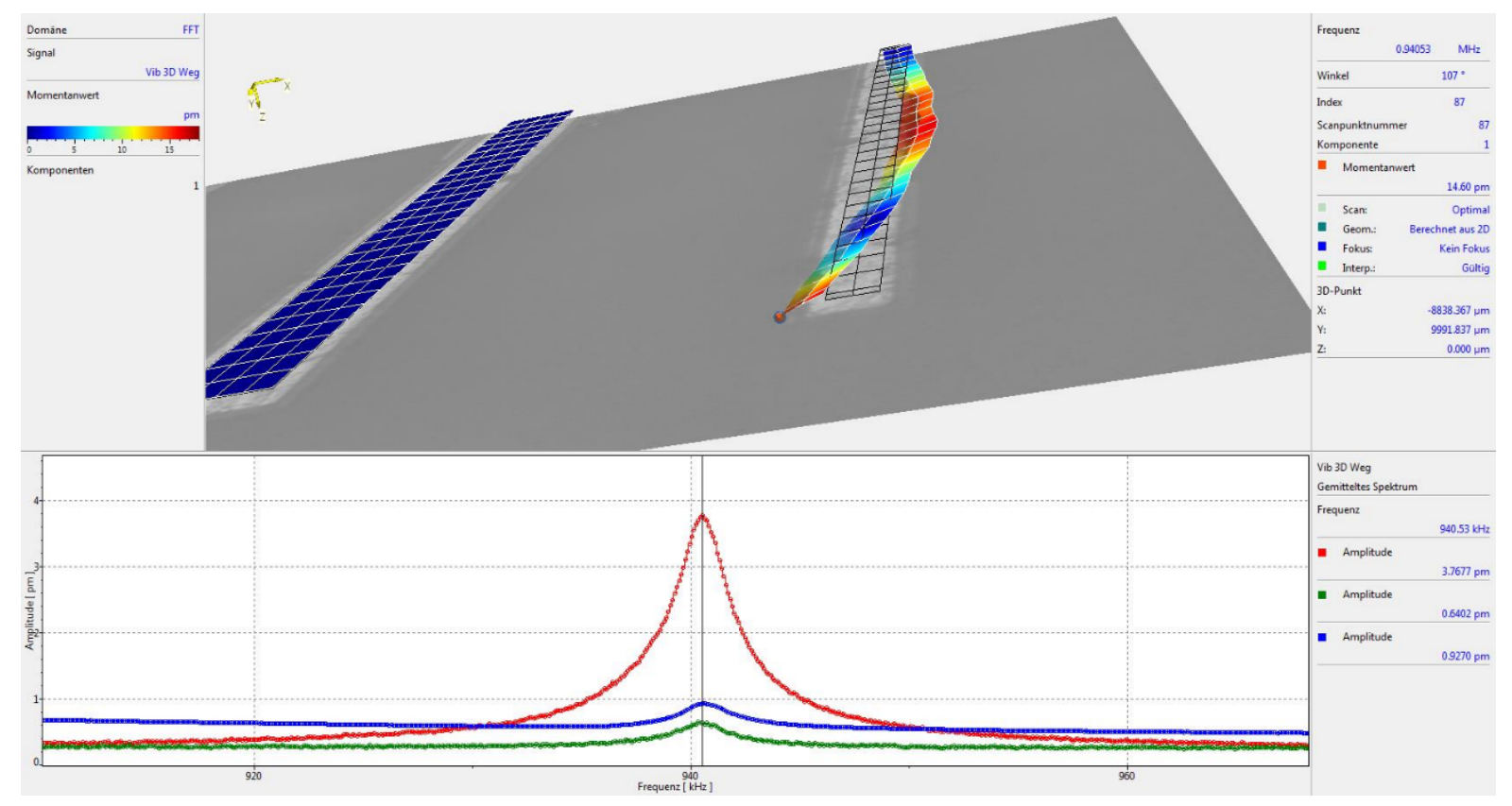

Figure 16: 3D displacement of PZT MEMS cantilever in higher order bending mode

\subsection{Multi-channel measurements}

Where multiple simultaneous non-contact measurements are desired or required, for example for transient vibrations on a delicate structure, use of individual LDVs quickly becomes a prohibitively costly solution. Multi-beam solutions have been proposed $[119,120]$ but with limited flexibility on beam orientations. More recent developments have seen user-configurable sensor heads [121, 122] connected to a central unit containing a single laser system and a multi-channel interferometric detection system. In the multi-point head shown in figure 17, eight sensor heads are connected to one optical unit [123]. Up to six optical units can be cascaded allowing configuration of up to 48 synchronous measurement channels. Inside the optical unit the output of the laser is split into eight measurement and eight reference channels. For each measurement channel, light is coupled into an optical fibre for that measurement head and focused on the measurement point on the structure of interest. Backscattered light is collected through the same lens and guided back to the optical unit for interferometric detection, using a second fibre. The interferometric signals from each channel are mixed down for demodulation. The flexibility afforded includes 3D measurement at a point by appropriate combination of a minimum of three sensor heads. 


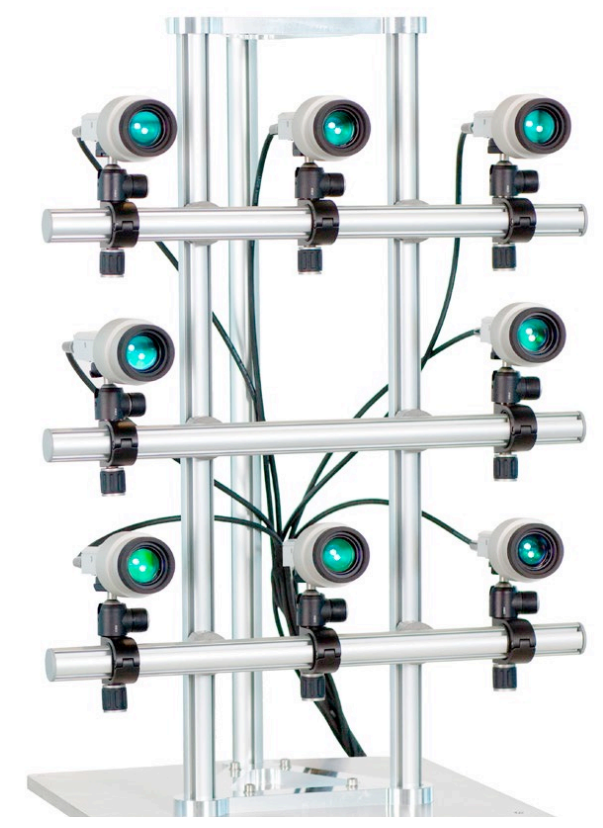

Figure 17: 8 channel optical setup of Polytec Multipoint Vibrometer

\section{Conclusions}

For over 30 years, the successes of LDV in providing measurement solutions in challenging applications have driven a culture of innovation in instrumentation without parallel amongst alternative vibration measurement techniques. Rather than satisfying the user community, these successes have inspired an apparently insatiable ambition. The further developments described in section 5 typify this but there are many more examples. The desire for long-range measurements without compromise to signal quality has seen the introduction of an instrument with a higher power infra-red (invisible) fibre laser, used in conjunction with a green laser for sighting purposes. The infrared laser technology is now migrating into instrument designs for short-range applications on optically less cooperative surfaces, finally challenging the supremacy of the HeNe laser after more than 50 years of LDV. For ultra-high frequency (up to $1.2 \mathrm{GHz}$ ) measurements on radio frequency MEMS resonators, a new algorithm [124] has found a legitimate means to breach a fundamental limit within frequency modulation theory to enable demodulation at frequencies higher than the carrier frequency. Meanwhile, at very low frequencies, seismic applications [125] have incentivised development of a technique to compensate for instrument vibration [126], recognising that LDVs, for all the successful applications, actually measure relative rather than absolute motion. Expectations remain high for the next 30 years in which many predict that multi-channel measurements will open up a new chapter in the story of LDV. 


\section{Acknowledgments}

The authors wish to acknowledge the many funding bodies that have contributed to their work. 


\section{References}

[1] Yeh Y, Cummins HZ. Localized fluid flow measurements with an He-Ne laser spectrometer. Applied Physics Letters. 1964; 4(10):176-8.

[2] Drain, L.E., 1980. The Laser Doppler Technique, Wiley, London, Chapter 9.

[3] Oldengarm J, Van Krieken AH, Raterink HJ. Laser Doppler velocimeter with optical frequency shifting. Optics \& Laser Technology. 1973; 5(6):249-52.

[4] Buchhave P. Laser Doppler velocimeter with variable optical frequency shift. Optics \& Laser Technology. 1975; 7(1):11-6.

[5] Halliwell NA. Laser-doppler measurement of vibrating surfaces: A portable instrument. Journal of Sound and Vibration. 1979; 62(2):312-5.

[6] Moss BC. The Harwell laser interferometer. UKAEA Atomic Energy Research Establishment; 1982.

[7] Bank G, Hathaway GT. A revolutionary 3-D interferometric vibrational mode display. In Audio Engineering Society Convention 66 1980. Audio Engineering Society.

[8] Stoffregen B, Felske A. Scanning laser Doppler vibration analysis system. SAE Technical Paper; 1985; 850327.

[9] Halliwell NA, Pickering CJ, Eastwood PG. The laser torsional vibrometer: a new instrument. Journal of Sound and Vibration. 1984; 93(4):588-92.

[10] J.C. Dainty, Laser Speckle and Related Phenomena, Springer-Verlag, 1975.

[11] McDevitt TE, Vikram CS. An investigation of pseudovibration signals in dual beam laser vibrometry. Review of scientific instruments. 1997; 68(4):1753-5.

[12] Vass J, Šmíd R, Randall RB, Sovka P, Cristalli C, Torcianti B. Avoidance of speckle noise in laser vibrometry by the use of kurtosis ratio: Application to mechanical fault diagnostics. Mechanical Systems and Signal Processing. 2008; 22(3):647-71.

[13] Hosek P. Algorithm for signal drop-out recognition in IC engine valve kinematics signal measured by laser Doppler vibrometer. Optics \& Laser Technology. 2012; 44(4):1101-12.

[14] Rothberg SJ, Baker JR, Halliwell NA. Laser vibrometry: pseudo-vibrations. Journal of Sound and Vibration. 1989; 135(3):516-22.

[15] Rothberg S. Numerical simulation of speckle noise in laser vibrometry. Applied Optics. 2006; 45(19):4523-33.

[16] Dräbenstedt A. Diversity combining in laser Doppler vibrometry for improved signal reliability. In 11th International Conference on Vibration Measurements by Laser Techniques: 
Advances and Applications 2014 (Vol. 1600, No. 1, pp. 263-273). AIP Conference Proceedings

[17] Halliwell NA. The laser torsional vibrometer: a step forward in rotating machinery diagnostics. Journal of Sound and Vibration. 1996; 190(3):399-418.

[18] Martin P, Rothberg SJ. Methods for the quantification of pseudo-vibration sensitivities in laser vibrometry. Measurement Science and Technology. 2011; 22(3):035302.

[19] Martin P, Rothberg SJ. Pseudo-vibration sensitivities for commercial laser vibrometers. Mechanical Systems and Signal Processing. 2011; 25(7):2753-65.

[20] Junge B. Experiences with scanning laser vibrometry in automotive industries. In $1^{\text {st }}$ International Conference on Vibration Measurements by Laser Techniques: 1994 (pp. 377 385). International Society for Optics and Photonics.

[21] Hancox J, Staples BC, Parker RJ. The application of scanning laser Doppler vibrometry in aero-engine development. Proceedings of the Institution of Mechanical Engineers, Part G: Journal of Aerospace Engineering. 1995; 209(1):35-42.

[22] Ewins D. Modal Testing: Theory, Practice, and Application. Research Studies Press; 2000.

[23] Stanbridge AB, Ewins DJ. Modal testing using a scanning laser Doppler vibrometer. Mechanical systems and signal processing. 1999; 13(2):255-70.

[24] Banwell GH, Roberts JR, Halkon BJ, Rothberg SJ, Mohr S. Understanding the dynamic behaviour of a tennis racket under play conditions. Experimental Mechanics. 2014; 54(4):527-37.

[25] Rembe C, Dräbenstedt A. Laser-scanning confocal vibrometer microscope: Theory and experiments. Review of scientific instruments. 2006; 77(8):083702.

[26] Giuliani P, Di Maio D, Schwingshackl CW, Martarelli M, Ewins DJ. Six degrees of freedom measurement with continuous scanning laser doppler vibrometer. Mechanical systems and signal processing. $2013 ; 38(2): 367-83$.

[27] Sriram P, Craig JI, Hanagud S. A scanning laser Doppler vibrometer for modal testing. International Journal of Analytical and Experimental Modal Analysis. 1990; 5(3):155-67.

[28] La J, Choi J, Wang S, Kim K, Park K. Continuous scanning laser Doppler vibrometer for mode shape analysis. Optical Engineering. 2003; 42(3):730-7.

[29] Stanbridge AB, Martarelli M, Ewins DJ. Measuring area vibration mode shapes with a continuous-scan LDV. Measurement. 2004; 35(2):181-9. 
[30] Stanbridge AB, Ewins DJ, Khan AZ. Modal testing using impact excitation and a scanning LDV. Shock and Vibration. 2000; 7(2):91-100.

[31] Vanlanduit S, Guillaume P, Schoukens J. Broadband vibration measurements using a continuously scanning laser vibrometer. Measurement Science and Technology. 2002; 13(10):1574-82.

[32] Martarelli M, Ewins DJ. Continuous scanning laser Doppler vibrometry and speckle noise occurrence. Mechanical Systems and Signal Processing. 2006; 20(8):2277-89.

[33] Allen MS, Sracic MW. A new method for processing impact excited continuous-scan laser Doppler vibrometer measurements. Mechanical Systems and Signal Processing. 2010; 24(3):721-35.

[34] Yang S, Allen MS. Harmonic transfer function to measure translational and rotational velocities with continuous-scan laser Doppler vibrometry. Journal of Vibration and Acoustics. 2014; 136(2):021025.

[35] Yang S, Allen MS. Output-only Modal Analysis using Continuous-Scan Laser Doppler Vibrometry and application to a 20kW wind turbine. Mechanical Systems and Signal Processing. 2012; 31:228-45.

[36] Davis QV, Kulczyk WK. Vibrations of turbine blades measured by means of a laser. Nature. $1969 ; 222: 475-6$.

[37] Buunen TJ, Vlaming MS. Laser-Doppler velocity meter applied to tympanic membrane vibrations in cat. The Journal of the Acoustical Society of America. 1981; 69(3):744-50.

[38] Ruggero MA, Rich NC. Application of a commercially-manufactured Doppler-shift laser velocimeter to the measurement of basilar-membrane vibration. Hearing research. 1991; 51(2):215-30.

[39] Riener TA, Goding AC, Talke FE. Measurement of head/disk spacing modulation using a two channel fiber optic laser Doppler vibrometer. IEEE Transactions on Magnetics. 1988; 24(6):2745-7.

[40] Bogy DB, Bouchard G, Chang WR, Talke FE. Use of the laser Doppler vibrometer to measure the surface topography of magnetic disks. Wear. 1986; 107(3):227-44.

[41] Cookson RA, Bandyopadhyay P. A fiber-optic laser-Doppler probe for vibration analysis of rotating machines. Journal of Engineering for Power. 1980; 102(3):607-12.

[42] Wlezein, RW, Miu DK, Kibens V. Characterization of rotating flexible disks using a laser Doppler vibrometer. Optical Engineering. 1984; 23(4):234436. 
[43] Halliwell NA, Pullen L, Baker J. Diesel engine health: laser diagnostics. SAE Technical Paper; 1983; No. 831324.

[44] Aicher B, Markl H, Masters WM, Kirschenlohr HL. Vibration transmission through the walking legs of the fiddler crab, Uca pugilator (Brachyura, Ocypodidae) as measured by laser Doppler vibrometry. Journal of comparative physiology. 1983; 150(4):483-91.

[45] $\mathrm{C}^{\sim} \mathrm{okl} \mathrm{A}$. Vibratory signal transmission in plants as measured by laser vibrometry. Periodicum biologorum. 1988; 90(2):193-6.

[46] Castellini P, Paone N, Tomasini EP. The laser doppler vibrometer as an instrument for nonintrusive diagnostic of works of art: application to fresco paintings. Optics and Lasers in Engineering. 1996; 25(4):227-46.

[47] Terasaki S, Wada N, Sakurai N, Muramatsu N, Yamamoto R, Nevins DJ. Nondestructive measurement of kiwifruit ripeness using a laser Doppler vibrometer. Transactions of the ASAE. 2001; 44(1):81.

[48] Marchionni P, Scalise L, Ercoli I, Tomasini EP. An optical measurement method for the simultaneous assessment of respiration and heart rates in preterm infants. Review of Scientific Instruments. 2013; 84(12):121705.

[49] Sabatier JM, Xiang N. An investigation of acoustic-to-seismic coupling to detect buried antitank landmines. IEEE transactions on geoscience and remote sensing. 2001; 39(6):114654.

[50] Khan AZ, Stanbridge AB, Ewins DJ. Detecting damage in vibrating structures with a scanning LDV. Optics and Lasers in Engineering. 1999; 32(6):583-92.

[51] Ghoshal A, Sundaresan MJ, Schulz MJ, Pai PF. Structural health monitoring techniques for wind turbine blades. Journal of Wind Engineering and Industrial Aerodynamics. 2000; 85(3):309-24.

[52] Waldron K, Ghoshal A, Schulz MJ, Sundaresan MJ, Ferguson F, Pai PF, Chung JH. Damage detection using finite element and laser operational deflection shapes. Finite Elements in Analysis and Design. 2002; 38(3):193-226.

[53] Staszewski WJ, Lee BC, Mallet L, Scarpa F. Structural health monitoring using scanning laser vibrometry: I. Lamb wave sensing. Smart Materials and Structures. 2004; 13(2):251.

[54] Kessler SS, Spearing SM, Atalla MJ, Cesnik CE, Soutis C. Damage detection in composite materials using frequency response methods. Composites Part B: Engineering. 2002; 33(1):87-95.

[55] Ostachowicz W, Radzieński M, Kudela P. 50th anniversary article: comparison studies of full 
wavefield signal processing for crack detection. Strain. 2014; 50(4):275-91.

[56] Vuye C, Vanlanduit S, Presezniak F, Steenackers G, Guillaume P. Optical measurement of the dynamic strain field of a fan blade using a 3D scanning vibrometer. Optics and Lasers in Engineering. 2011; 49(7):988-97.

[57] Di Maio D, Zampognaro N, Zang C, Ewins DJ. Effect of vibration excitation locations on structural damage detection using the CSLDV technique: simulation and testing. In 7 th International Conference on Vibration Measurements by Laser Techniques 2006 (pp. 63450O-63450O). International Society for Optics and Photonics.

[58] Di Maio D. Damage monitoring using Continuous Scanning LDV methods: numerical approach. In Dirckx, J (ed) 6th International Conference on Optical Measurement Techniques for Structures and Systems III (OPTIMESS2015), Antwerp, BELGIUM, pp.61-71

[59] Rembe C, Muller RS. Measurement system for full three-dimensional motion characterization of MEMS. Journal of Microelectromechanical Systems. 2002; (5):479-88.

[60] Rembe C, Kowarsch R, Ochs W, Dräbenstedt A, Giesen M, Winter M. Optical threedimensional vibrometer microscope with picometer-resolution in $\mathrm{x}, \mathrm{y}$, and $\mathrm{z}$. Optical Engineering. 2014; 53(3):034108.

[61] Vignola JF, Liu X, Morse SF, Houston BH, Bucaro JA, Marcus MH, Photiadis DM, Sekaric L. Characterization of silicon micro-oscillators by scanning laser vibrometry. Review of scientific instruments. 2002; 73(10):3584-8.

[62] Judge JA, Vignola JF, Jarzynski J. Dissipation from microscale and nanoscale beam resonators into a surrounding fluid. Applied Physics Letters. 2008; 92(12):124102.

[63] Ilic B, Craighead HG, Krylov S, Senaratne W, Ober C, Neuzil P. Attogram detection using nanoelectromechanical oscillators. Journal of Applied Physics. 2004; 95(7):3694-703.

[64] Oberholster AJ, Heyns PS. Eulerian laser Doppler vibrometry: Online blade damage identification on a multi-blade test rotor. Mechanical Systems and Signal Processing. 2011; 25(1):344-59.

[65] Di Maio D, Ewins DJ. Applications of continuous tracking SLDV measurement methods to axially symmetric rotating structures using different excitation methods. Mechanical Systems and Signal Processing. 2010; 24(8):3013-36.

[66] Drew SJ, Stone BJ. Torsional (rotational) vibration: excitation of small rotating machines. Journal of sound and vibration. 1997; 201(4):437-63. 
[67] Collette C, Preumont A. Laser measurement of torsional vibrations/longitudinal creepage of a railway wheel set on a scaled test bench. Optics and Lasers in Engineering. 2009; 47(3):3859.

[68] Martin P, Rothberg SJ. Differential measurements using two laser rotational vibrometers: dynamic backlash. In 7th International Conference on Vibration Measurements by Laser Techniques 20069 (pp. 63450N-63450N). International Society for Optics and Photonics.

[69] Halkon B, Rothberg SJ. Automatic post-processing of laser vibrometry data for rotor vibration measurements. In 8th International Conference on Vibrations in Rotating Machinery, University of Wales, Swansea, UK. 2004 (pp. 215-229).

[70] Castellini P, Santolini C. Vibration measurements on blades of a naval propeller rotating in water with tracking laser vibrometer. Measurement. 1998; 24(1):43-54.

[71] Castellini P, Paone N. Development of the tracking laser vibrometer: performance and uncertainty analysis. Review of Scientific Instruments. 2000; 71(12):4639-47.

[72] Castellini P, Montanini R. Automotive components vibration measurements by tracking laser Doppler vibrometry: advances in signal processing. Measurement Science and Technology. 2002; 13(8):1266.

[73] Dietzhausen H, Bendel K, Scelles N. Tracking scanning laser Doppler vibrometers: extending laser vibrometry to arbitrarily moving objects. Proceedings of IMAC XXI. Kissimmee, Florida, 2003, Paper \#168.

[74] Halkon BJ, Rothberg SJ. Synchronized-scanning laser vibrometry. In 6th International Conference on Vibration Measurements by Laser Techniques 2004 (pp. 260-271). International Society for Optics and Photonics.

[75] Di Maio D, Ewins DJ. CAISER MYMESIS: a new software platform for virtual and actual vibration testing on rotating structures using a continuously scanning LDV technique. In 7 th International Conference on Vibration Measurements by Laser Techniques 2006 (pp. 63450Q-63450Q). International Society for Optics and Photonics.

[76] Castellini P, Tomasini EP. Image-based tracking laser Doppler vibrometer. Review of scientific instruments. 2004; 75(1):222-32.

[77] Sever IA, Stanbridge AB, Ewins DJ. Turbomachinery blade vibration measurements with tracking LDV under rotation. In 7th International Conference on Vibration Measurements by Laser Techniques 2006 (pp. 63450L-63450L). International Society for Optics and Photonics.

[78] Rothberg SJ, Tirabassi M. Development of a scanning head for laser Doppler vibrometry (LDV) using dual optical wedges. Review of Scientific Instruments. 2013; 84(12):121704.. 
[79] Polytec Application Note, 2010. http://www.polytec.com/eu/products/vibrationsensors/scanning-vibrometers/psv-a-440-optical-derotator/ (October 2016).

[80] Rothberg SJ, Tirabassi M. A universal framework for modelling measured velocity in laser vibrometry with applications. Mechanical Systems and Signal Processing. 2012; 26:141-66.

[81] Lee KM, Polycarpou AA. Dynamic microwaviness measurements of super smooth disk media used in magnetic hard disk drives. Mechanical systems and signal processing. 2006; 20(6):1322-37.

[82] Jiang Q, Bi C, Lin S. Accurate runout measurement for HDD spinning motors and disks. Journal of Advanced Mechanical Design, Systems, and Manufacturing. 2010; 4(1):324-35.

[83] Prasad BS, Sarcar MM, Ben BS. Development of a system for monitoring tool condition using acousto-optic emission signal in face turning — an experimental approach. The International Journal of Advanced Manufacturing Technology. 2010; 51(1-4):57-67.

[84] Tatar K, Gren P. Measurement of milling tool vibrations during cutting using laser vibrometry. International Journal of Machine Tools and Manufacture. 2008; 48(3):380-7.

[85] Rothberg SJ, Halliwell NA. Vibration measurements on rotating machinery using laser Doppler velocimetry. Journal of vibration and acoustics. 1994; 116(3):326-31.

[86] Halkon BJ, Rothberg SJ. Rotor vibration measurements using laser Doppler vibrometry: essential post-processing for resolution of radial and pitch/yaw vibrations. Journal of vibration and acoustics. 2006; 128(1):8-20.

[87] Tatar K, Rantatalo M, Gren P. Laser vibrometry measurements of an optically smooth rotating spindle. Mechanical systems and signal processing. 2007; 21(4):1739-45.

[88] Rothberg SJ, Halkon BJ, Tirabassi M, Pusey C. Radial vibration measurements directly from rotors using laser vibrometry: The effects of surface roughness, instrument misalignments and pseudo-vibration. Mechanical Systems and Signal Processing. 2012; 33:109-31.

[89] Halkon BJ, Rothberg SJ. Angular (pitch and yaw) vibration measurements directly from rotors using laser vibrometry. Mechanical Systems and Signal Processing. 2014; 46(2):34460.

[90] Willemin JF, Dändliker R, Khanna SM. Heterodyne interferometer for submicroscopic vibration measurements in the inner ear. The Journal of the Acoustical Society of America. 1988; 83(2):787-95.

[91] Rosowski JJ, Ravicz ME, Teoh SW, Flandermeyer D. Measurements of middle-ear function in the Mongolian gerbil, a specialized mammalian ear. Audiology and Neurotology. 1999; 4(3-4):129-36. 
[92] Decraemer WF, de La Rochefoucauld O, Funnell WR, Olson ES. Three-dimensional vibration of the malleus and incus in the living gerbil. Journal of the Association for Research in Otolaryngology. 2014; 15(4):483-510.

[93] Aerts JR, Dirckx JJ. Nonlinearity in eardrum vibration as a function of frequency and sound pressure. Hearing research. 2010; 263(1):26-32.

[94] Peacock J, Pintelon R, Dirckx J. Nonlinear Vibration Response Measured at Umbo and Stapes in the Rabbit Middle ear. Journal of the Association for Research in Otolaryngology. 2015; 16(5):569-80.

[95] Huber AM, Ma F, Felix H, Linder T. Stapes prosthesis attachment: the effect of crimping on sound transfer in otosclerosis surgery. The Laryngoscope. 2003; 113(5):853-8.

[96] Huber AM, Ball GR, Veraguth D, Dillier N, Bodmer D, Sequeira D. A new implantable middle ear hearing device for mixed hearing loss: a feasibility study in human temporal bones. Otology \& neurotology. 2006; 27(8):1104-9.

[97] Waldmann B, Maier H, Leuwer R, 2003. Indicators for efficient coupling of the Otologics MET ossicular stimulator. In: Gyo, K., Wada, H. (Eds.), 3rd symposium of middle ear mechanics in research and otology, Matsuyama, Ehime, Japan.

[98] Muyshondt PG, Soons JA, De Greef D, Pires F, Aerts P, Dirckx JJ. A single-ossicle ear: Acoustic response and mechanical properties measured in duck. Hearing research. 2016; 340:35-42.

[99] Moreno JN. Measurement of loudspeaker parameters using a laser velocity transducer and 2channel FFT analysis. Journal of the Audio Engineering Society. 1991; 39(4):243-249

[100] Suh JG, Kim HY, Yôiti S. Measurement of resonance frequency and loss factor of a microphone diaphragm using a laser vibrometer. Applied Acoustics. 2010; 71(3):258-61.

[101] Zipser L, Franke H. Laser-scanning vibrometry for ultrasonic transducer development. Sensors and Actuators A: Physical. 2004; 110(1):264-8.

[102] Huber TM. Measurement of mode shapes of musical instruments using a scanning laser Doppler vibrometer. The Journal of the Acoustical Society of America. 2011; 129(4):2615-.

[103] Bissinger G, Oliver D. 3-D laser vibrometry on legendary old Italian violins. Sound and Vibration. 2007; 41(7):10-5.

[104] Zoran A, Welch S, Hunt WD. A platform for manipulation and examination of the acoustic guitar: The Chameleon Guitar. Applied Acoustics. 2012; 73(4):338-47.

[105] Ryan T, O'Malley P, Glean A, Vignola J, Judge J. Conformal scanning laser Doppler vibrometer measurement of tenor steelpan response to impulse excitation. The Journal of the 
Acoustical Society of America. 2012; 132(5):3494-501.

[106] Perrin R, Elford DP, Chalmers L, Swallowe GM, Moore TR, Hamdan S, Halkon BJ. Normal modes of a small gamelan gong. The Journal of the Acoustical Society of America. 2014; 136(4):1942-950.

[107] Martarelli M, Revel GM. Laser Doppler vibrometry and near-field acoustic holography: Different approaches for surface velocity distribution measurements. Mechanical systems and signal processing. 2006; 20(6):1312-21.

[108] Fischer M, Bendel K, Mitchell P, Steger H. Hot on the trail of squealing brakes-3-D vibrometry makes noise sources visible. Sound and Vibration. 2005; 39(7): 7-8.

[109] Revel GM, Martarelli M, Chiariotti P. A new laser vibrometry-based 2D selective intensity method for source identification in reverberant fields: part II. Application to an aircraft cabin. Measurement Science and Technology. 2010; 21(7): p. 075108.

[110] Zheng J, Pan J, Huang H. An experimental study of winding vibration of a single-phase power transformer using a laser Doppler vibrometer. Applied Acoustics. 2015; 87:30-7.

[111] Roozen NB, Labelle L, Rychtáriková M, Glorieux C. Determining radiated sound power of building structures by means of Laser Doppler vibrometry. Journal of Sound and Vibration. $2015 ; 346: 81-99$.

[112] Vignola JF, Berthelot YH, Jarzynski J. Laser detection of sound. The Journal of the Acoustical Society of America. 1991; 90(3):1275-86.

[113] Leclère Q, Laulagnet B. Particle velocity field measurement using an ultra-light membrane. Applied Acoustics. 2008; 69(4):302-10.

[114] Pitts TA, Greenleaf JF. Three-dimensional optical measurement of instantaneous pressure. The Journal of the Acoustical Society of America. 2000; 108(6):2873-83.

[115] Zipser L, Franke H, Olsson E, Molin NE, Sjödahl M. Reconstructing two-dimensional acoustic object fields by use of digital phase conjugation of scanning laser vibrometry recordings. Applied optics. 2003; 42(29):5831-8.

[116] Harland AR, Petzing JN, Tyrer JR, Bickley CJ, Robinson SP, Preston RC. Application and assessment of laser Doppler velocimetry for underwater acoustic measurements. Journal of sound and vibration. 2003; 265(3):627-45.

[117] Vanherzeele J, Longo R, Vanlanduit S, Guillaume P. Tomographic reconstruction using a generalized regressive discrete Fourier series. Mechanical Systems and Signal Processing. 2008; 22(5):1237-47.

[118] Vanlanduit S, Vanherzeele J, Guillaume P, De Sitter G. Absorption measurement of acoustic 
materials using a scanning laser Doppler vibrometer. The Journal of the Acoustical Society of America. 2005; 117(3):1168-72.

[119] MacPherson WN, Reeves M, Towers DP, Moore AJ, Jones JD, Dale M, Edwards C. Multipoint laser vibrometer for modal analysis. Applied optics. 2007; 46(16):3126-32.

[120] Kilpatrick JM, Markov V. Matrix laser vibrometer for transient modal imaging and rapid nondestructive testing. In 8th International Conference on Vibration Measurements by Laser Techniques: Advances and Applications 2008 Jun 4 (pp. 709809-709809). International Society for Optics and Photonics.

[121] Phua PB, Fu Y, Guo M, Liu H. Multi-beam Laser Doppler Vibrometer with fiber sensing head. In 10th International Conference on Vibration Measurements by Laser Techniques 2012 (Vol. 1457, No. 1, pp. 219-226). AIP Publishing.

[122] Haist T, Lingel C, Osten W, Winter M, Giesen M, Ritter F, Sandfort K, Rembe C, Bendel K. Multipoint vibrometry with dynamic and static holograms. Review of Scientific Instruments. 2013; 84(12):121701.

[123] http://www.multipoint-vibrometer.de/files/polytec/pdf/MPV 800 E Preliminary.pdf (October 2016)

[124] Rembe C. Employing applied mathematics to expand the bandwidth of heterodyne carrier signals with a small phase modulation index. Applied Mathematics and Computation. 2010; 217(3):1202-12.

[125] Dräbenstedt A, Cao X, Polom U, Pätzold F, Zeller T, Hecker P, Seyfried V, Rembe C. Mobile seismic exploration. In 12th International Conference on Vibration Measurements by Laser Techniques 2016 (Vol 1740, p. 030001). AIP Publishing

[126] Halkon BJ, Rothberg SJ. Taking laser Doppler vibrometry off the tripod: correction of measurements affected by instrument vibration. Submitted to Optics and Lasers in Engineering. 